\title{
Bow-Echo Mesovortices: A Review
}

\author{
Alexander D. Schenkman ${ }^{1}$ and Ming Xue ${ }^{1,2}$ \\ Center for Analysis and Prediction of Storms ${ }^{1}$ and School of Meteorology ${ }^{2}$ \\ University of Oklahoma, Norman Oklahoma 73072
}

\author{
July 2015 \\ Revised: September 2015 \\ $2^{\text {nd }}$ Revision: October 2015 \\ Submitted to Atmospheric Research \\ Corresponding author address: \\ Alexander D. Schenkman \\ Center for Analysis and Prediction of Storms \\ University of Oklahoma, \\ 120 David L. Boren Blvd, Norman OK 73072 \\ alex3238@ou.edu
}




\section{Abstract}

Non-supercellular damaging winds from convective storms are overwhelmingly associated with

3 quasi-linear convective systems. A review of early studies of these systems suggested that wind

4 damage/speed was not continuous and instead was enhanced over many small areas. More recent

5 research has revealed a close association between damaging winds, tornadoes, and low-level meso- $\gamma-$

6 scale vortices (mesovortices) that develop within the convective portion of QLCSs. Observational and

7 numerical studies are reviewed to explain the relationship between mesovortices, damaging winds, and

8 tornadoes. Substantial disagreement exists with regard to the processes responsible for the genesis of

9 these mesovortices. Nonetheless, case study simulations of real events have been successful in

10 simulating mesovortices in both a deterministic and probabilistic framework. Implications and

11 recommendations for future work in a warn-on-forecast context are provided. 


\section{Introduction}

In the United States, the vast majority of non-supercellular tornadoes and damaging winds occur in meso- $\beta$-scale (20-200 km; Orlanski 1975) quasi-linear convective systems (QLCS), such as squall lines and bow-echoes (Trapp et al. 2005). The structure of bow echoes (a type of QLCS that develops into a bowshaped radar reflectivity echo structure) and their association with damaging winds was first studied in detail by Fujita and collaborators in the late 1970s and early 1980s. Specifically, Fujita (1978) studied radar imagery and developed a conceptual model that describes the life cycle of the bow echo (Fig. 1). In this conceptual model, the system begins as a single 'tall echo' and then proceeds to develop into a 'bow echo' that eventually develops a rotating comma-echo during its mature and decay phase. Fujita (1978; 1979) identified the apex of the bow-echo as an area where a downburst, defined as a strong downdraft that induces an outburst of damaging winds on or near the ground, could lead to wind damage and possibly tornadoes.

Initial work studying the structure of bow-echoes focused on larger system-scale features such as the development of mid-level counter-rotating, or 'book-end', vortices (e.g., Weisman 1992, 1993), trailing mid-level mesoscale convective vortices (e.g., Johnston 1981; Houze et al. 1989; Menard and Fritsch 1989; Jorgensen and Smull 1993; Skamarock et al. 1994) and the rear-inflow jet (RIJ), an area of mid-level rear-to-front flow that extends from the stratiform to the convectively active portion of QLCSs (e.g., Fujita 1981; Smull and Houze 1987; Klimowski 1994). RIJs have been implicated in the production of damaging winds as well as in creating a horizontal vorticity balance that allows for long-lived bow echoes (Weisman 1993).

In addition to examining the effects of the RIJ on system longevity, Weisman (1993) used idealized simulations of bow-echoes to explore the generation of book-end vortices and proposed that book-end vortices were the result of system-scale tilting of environmental vorticity by the system scale updraft and downdraft. Furthermore, Weisman (1993) pointed out that the book-end vortices acted to 
accelerate and focus the system's RIJ which led to severe winds at the bow-apex (Fig. 2). Weisman (1993) also suggested that more careful analysis was necessary to determine the role of the systemgenerated (baroclinic) vorticity. Drawing on this suggestion, Weisman and Davis (1998) set out to determine the relative contribution of the ambient and system-generated baroclinic vorticity in the development of system and sub-system scale mid-level line-end vortices (a more general term than

42 'bookend' for vortices that develop at the ends of convective line segments) based on detailed diagnostic analyses of idealized numerical simulations. Their study determined that tilting of the systemgenerated vorticity was the leading order cause of line-end vortices (Fig. 3). They clarified that the role of environmental shear was to promote more intense and upright upward motion along the system's leading edge thus promoting more intense vortices. Moreover, Weisman and Davis (1998) found that the cyclonic (anti-cyclonic) vortex was enhanced (weakened) by the convergence of Coriolis rotation.

Over the past two decades, higher-resolution observations, numerical simulations, and the implementation of the Weather Surveillance Radar - 1988 Doppler (WSR-88D) radar network have provided opportunities for more detailed study of the severe winds and tornadoes within larger-scale bow echoes. These studies have revealed the existence of low-level meso- - -scale $(2-20 \mathrm{~km}$; Orlanski 1975) vortices (hereafter; mesovortices). These mesovortices have been found to be closely linked with swaths of high winds and tornadoes in QLCSs. It is important to distinguish that mesovortices are distinctly a low-level feature that are generally smaller in scale than book-end vortices, and may occur anywhere within the convectively-active portion of a QLCS, rather than only at the end of the line segment. Moreover, they are considerably smaller than trailing mid-level mesoscale-convective vortices

57 (MCVs; e.g., Johnston 1981; Menard and Fritsch 1989).

The remainder of this paper will focus on reviewing the characteristics, dynamics, and successful prediction of mesovortices. In particular, section 2 will present a general overview of the observations and simulations of mesovortices and their relationship to damaging winds and tornadoes. Mesovortex 
61 genesis mechanisms will be discussed in section 3 . Section 4 will examine two case studies in which

62 mesovortices and their parent storm system were successfully predicted using high-resolution numerical

63 simulations and data assimilation. A summary and a discussion of key results with implications for

64 future study are presented in section 5.

65

66

67

68

69

70

71

72

73

74

75

76

77

78

79

80

81

82

83

\section{Mesovortices, damaging winds, and tornadoes}

As mentioned in the introduction, over the past 20 years, studies have noted the presence of lowlevel mesovortices embedded within the leading edge convection of QLCSs. The term "mesovortex" was first used in Przybylinski (1995) in reference to a strong vortex near the northern end of a rapidly moving squall line. Weisman and Trapp (2003; hereafter WT03) more formally defined mesovortices as significant low-level meso- $\gamma$ scale vortices that form within QLCSs. They note that these mesovortices were similar in size and structure to low-level mesocyclones in supercells but differ in that they are generally not accompanied by a mid-level mesocyclone. In this section, the relationship between mesovortices, damaging winds, and tornadoes is explored by reviewing observational and modeling studies. Because the term 'mesovortex' was not formally defined until WT03, several of the cited studies used different terminology to discuss what may have been mesovortices.

\subsection{Observational studies}

Fujita and Wakimoto (1981) studied a damaging wind event that occurred from Chicago to Detroit on 16 July 1980. From careful analysis of damage patterns produced by the event, they identified five scales of downburst wind damage (Fig. 4). Their study noted that downbursts typically occurred in clusters with microbursts and embedded very small-scale 'burst swaths'. Fujita and Wakimoto (1981) also made a distinction between the winds associated with the gust front and the 
stronger winds associated with 'downbursts'. Building upon the work of Fujita and Wakimoto (1981),

85 Forbes and Wakimoto (1983) present a detailed study of a mesoscale convective system (MCS) that produced numerous tornadoes, downbursts, and microbursts on 6 August 1977 near Springfield, IL.

87 They found that the tornadoes and downbursts occurred in association with a bow-echo during this event. Moreover, the tornadoes seemed to be associated with downbursts as well as with the rotating comma head of the convective system. They noted that hook echoes were not observed and that the "tornadoes appeared to develop in conjunction with wind shears associated with the gust front and with

91 microbursts." Though Fujita and Wakimoto (1981) and Forbes and Wakimoto (1983) did not have

92 Doppler radar data to analyze the radial velocity in the storms they analyzed, the location and description of these tornadoes and downbursts suggests that the some of features they are describing were potentially related to mesovortices.

Though Fujita and collaborators cleverly deduced the wind structure in hindsight from damage surveys, a more detailed understanding of the structure of the MCS wind field required the availability

97 of Doppler radar observations. To prepare forecasters for interpreting the operational WSR-88D radar data, Przybylinski (1995) presented a survey of bow-echoes as observed by Doppler radar systems. He noted that mesoscale vortices had been observed near the bow apex and northern end of squall lines (Burgess and Smull 1990). The greatest wind damage was generally associated with these vortices and tornadoes near the bow echo apex. Przybylinski suggested that shearing instability may be the root cause for these vortices. Trapp et al. (1999) also speculated shearing instability was responsible for the development of a series of mesovortices along the line-echo wave pattern they studied.

Radar data sets of bow echoes and mesovortices became more plentiful following the operational deployment of the WSR-88D network. Pfost and Gerard (1997) and Wolf (1998) 106 documented two cases where tornadoes developed in association with the comma-echo phase of a 107 QLCS. Funk et al. (1999) presented a detailed study of a derecho that occurred over Kentucky and 
southern Indiana on 15 April 1994. Funk et al. (1999) noted that damaging wind occurrences in this

109 system were closely tied to the development of mesocyclone-scale vortices at low-levels at the bow-

110 apex and associated with the comma head of the QLCS. Vortices that were longer-lived and deeper

111 were observed to produce tornadoes and more widespread damaging wind swaths. Weaker vortices

112 also produced damaging winds but were non-tornadic. Funk et al. (1999) also speculated that shearing

113 instability was important in the formation these vortices.

Atkins et al. (2004; 2005) built upon the work of Funk et al. (1999) and studied the 115 characteristics of observed mesovortices and their relationship to tornadoes and high winds. 116 Specifically, Atkins et al. (2004) studied a severe bow echo that occurred in June 1998 over southeast 117 lowa into central/eastern Illinois and found that tornadic mesovortices tended to have a significantly 118 longer life-span than non-tornadic mesovortices. Moreover, tornadic mesovortices had much stronger 119 rotational velocities than their non-tornadic counterparts. The differences in rotational velocities were 120 most pronounced at low levels. Based on these observations, Atkins et al. (2004) suggested it may be 121 possible to distinguish between tornadic and non-tornadic mesovortices in an operational setting. 122 Atkins et al. (2005), based on the study of a different severe bow-echo case that occurred near Saint 123 Louis, also found that tornadic mesovortices were longer-lived and stronger than non-tornadic 124 mesovortices. Mesovortices were also observed to be coincident with most of the damaging straight125 line winds produced by the bow echo studied in Atkins et al. (2005). In addition, Atkins et al. (2005) 126 observed that tornadic mesovortices were stronger than non-tornadic mesovortices, even prior to 127 tornadogenesis, which could be promising for operational forecasters trying to provide accurate tornado 128 warnings. However, Atkins et al. (2005) also found that tornadogenesis occurred, on average, only 12 129 min after mesovortex genesis suggesting that forecasters would have very little lead time. Finally, Atkins 130 et al. (2005) suggested that mesovortices were more likely to become tornadic if they were in close 131 proximity to the RIJ possibly owing to stronger stretching associated with enhanced convergence. 
The link between mesovortices and damaging winds was solidified by Wheatley et al. (2006).

133 They surveyed the MCS cases observed during the Bow Echo and Mesoscale Convective Vortex 134 Experiment (BAMEX; Davis et al. 2004) and found that, while damaging winds occurred in MCSs that did 135 not produce low-level mesovortices, the most intense wind damage was associated with the MCSs that 136 did produce mesovortices. Moreover, Wheatley et al. (2006) found that these intense damaging winds 137 were generally spawned on the south side of the mesovortices. Similar results were found in the QLCS 138 studied by Wakimoto et al. (2006a; 2006b). Additionally, Wakimoto et al. (2006b) used a flow 139 decomposition to determine that damaging winds in mesovortices were the result of the superposition 140 of the mesovortex flow with the rear-inflow jet (Fig. 5).

\subsection{Modelling studies}

Accurate numerical simulations afford the opportunity to examine dynamic relationships and 144 parameter spaces in much more detail than observational studies. The association between 145 mesovortices and high winds has been examined in the model simulations of WT03, Trapp and Weisman 146 (2003; hereafter TW03), Atkins and St. Laurent (2009a), and Xu et al. (2015a). WT03 used the Klemp 147 and Wilhelmson (1978) 3D cloud model to simulate the behavior of mesovortices in various windshear 148 regimes. Their experiments included the impact of the intensity and depth of environmental vertical 149 shear on mesovortex behavior. In general, WT03 found that stronger vertical shear led to stronger 150 simulated mesovortices. This was especially the case when the shear was confined to the lowest few 151 kilometers rather than a deeper layer (i.e., $0-7.5 \mathrm{~km}$ shear). They attributed this result to the fact that 152 stronger environmental shear promoted stronger, more upright updrafts which led to more intense 153 vortex stretching. WT03 also provided a detailed comparison of the dynamical properties of 154 supercellular mesocyclones and mesovortices. Specifically, WT03 showed that, in stark contrast to 155 supercellular mesocyclones, bow-echo mesovortices were distinctly a low-level feature that were not 
associated with the upward dynamic vertical pressure gradient forcing inherent in a pre-existing deep

157 rotating updraft. Moreover, owing to the lack of dynamic updraft forcing, mesovortices do not exhibit 158 significant off-hodograph propagation implying that streamwise vorticity is less important in their 159 generation making the concept of storm-relative environmental helicity somewhat irrelevant in their 160 prediction. WT03 also explained that low-level rotation maximized at the ground implied a downward 161 vertical pressure gradient force which TW03 showed acts to fracture convective lines causing the QLCS 162 to becoming segmented (Fig. 6a).

TW03 analyzed the results of WTO3 and found that the strongest surface winds in the simulated 164 MCSs were associated with mesovortices. TW03 ruled out downbursts for the intense winds because 165 they noted the simulated intense winds descend fairly slowly from aloft. Instead, TW03 concluded that 166 damaging winds were driven by the horizontal pressure gradient force associated with pressure deficits 167 in the mesovortices. As such, parcels were initially accelerated by the cold pool and then dramatically 168 accelerated by the pressure drop associated with the mesovortex (see the gray stippled region in Fig. 169 6a). This led to the strongest winds occurring in conjunction with the mesovortices.

170 Atkins and St. Laurent (2009a) also examined the relationship of mesovortices to the strength of the 171 low-level shear but used the Weather Research and Forecasting (WRF; Skamarock and Klemp 2008) 172 model instead of the Klemp and Wilhelmson model. As in TW03, they found that mesovortices were 173 strongest for moderate-to-strong low-level shear. They also attributed this tendency to the fact that 174 stronger low-level shear favored deeper, more upright updrafts that enhanced vorticity stretching and 175 longevity of the simulated mesovortices. Unlike TW03, Atkins and St. Laurent (2009a) determined that 176 the intense surface winds associated with mesovortices were the result of the linear superposition of 177 the descending rear-inflow jet and the flow associated with the mesovortex (Fig. 6b). This result is in 178 agreement with the flow decomposition presented in Wakimoto et al. (2006b). 
Noting that previous modeling studies of mesovortices all were performed with homogeneous initial conditions but observational studies (e.g., Przbylinski et al. 2000) had suggested that mesoscale heterogeneity impacted the development of mesovortices, Wheatley and Trapp (2008) investigated the impact of mesoscale heterogeneity on mesovortices. Specifically, through numerical simulations of real cases that included heterogeneous environmental flows, Wheatley and Trapp (2008) concluded that environmental heterogeneity does not play a direct role in mesovortex genesis but could substantially impact mesovortex intensity. More specifically, meso- $\gamma$-scale heterogeneity (e.g., a convective gust front from a storm external to the MCS) was found to enhance vorticity stretching and thus lead to mesovortex intensification. On the meso- $\beta$-scale, a frontal boundary altered the environmental shear such that updrafts were stronger on the cool side of the frontal boundary, leading to more intense mesovortices there when compared to the warm side of the frontal boundary.

While the observation studies discussed in section 2.1 noted a correspondence between mesovortices and tornadoes, the dynamical relationship between the phenomena has been relatively unexplored in the literature. To the author's knowledge, only Schenkman et al. (2012) has simulated mesovortices with sufficient resolution to capture tornado-like phenomena. Their study simulated a

194 long-lived, tornadic mesovortex with 100-m model grid spacing. Fig. 7 presents their schematic 195 depiction of tornadogenesis in the simulated event. In this schematic, a tornado-like vortex ${ }^{1}$ develops 196 within the mesovortex as vorticity is concentrated by low-level convergence associated with an intense 197 low-level updraft on the west side of the mesovortex. Interestingly, this low-level updraft was 198 determined to be the upward branch of a strong horizontal rotor circulation. The vorticity for the rotor 199 was found to be generated by surface drag in the low-level inflow to the mesovortex. It is unknown if this type of rotor circulation is a common occurrence with tornadic mesovortices. More simulations and

\footnotetext{
${ }^{1}$ Schenkman et al. 2012 call the vortex 'tornado-like' because their simulation did not have adequate resolution to fully resolve the tornado-scale processes associated with the strong sub-mesovortex-scale vortex.
} 
201 detailed observational studies are required to explore the relationship between mesovortices and 202 tornadoes.

\section{3. Mesovortex genesis}

Now that the relationship between mesovortices, damaging winds, and tornadoes has been

205 reviewed, we turn our attention to the processes behind mesovortex-genesis. With one exception

206 (Wakimoto et al. 2006b), studies of mesovortex-genesis have been based upon numerically simulated

207 convective systems. Several distinct conceptual models have emerged for mesovortex formation. As of

208 this review, there is no reconciliation or agreement about what conceptual model is more generally

209 correct or applicable.

\subsection{Downward vortex line tilting - The Trapp and Weisman model}

As discussed above, TW03 and WT03 examined quasi-idealized simulations of MCSs over a

213 broad range of environmental shear profiles. During the early stage of the simulated MCS, the 214 mesovortices began as vorticity couplets immediately behind the system gust front, with the cyclonic 215 (anticyclonic) member on the south (north) side of a rainy downdraft. As such, TW03 surmise that 216 these mesovortices are generated via the downward tilting of baroclinically generated vorticity by a 217 localized downdraft associated with a rainwater maximum (Fig. 8a). During the mature stage of the 218 MCS, TW03 found that vortex couplets were formed via tilting of horizontal vorticity associated with 219 vertical shear underneath the RIJ. The downdraft responsible for tilting in the mature stage was broader 220 and located several kilometers to the rear of convective gust front. Interestingly, in both the early and 221 mature cases, the symmetry of the vorticity couplet is broken in experiments that include Coriolis 222 forcing. In those experiments, the cyclonic vorticity becomes dominant, developing into a strong, long223 lived mesovortex. In experiments that do not include Coriolis forcing, neither the cyclonic nor anti- 
224 cyclonic vortex become strong. As such, TW03 conclude that Coriolis forcing is critical in the 225 development of intense mesovortices.

Wakimoto et al. (2006b) examined the genesis of mesovortices via an airborne dual-Doppler

227 radar analysis. They found that vortex couplets developed with the same orientation (i.e., the anti-

228 cyclonic vortex was north of the cyclonic vortex) to the simulation of TW03. However, Wakimoto et al.

229 (2006b) found that the vorticity couplets formed in an area devoid of precipitation which led them to

230 conclude that rainy downdrafts could not be leading to the depression of baroclinically generated vortex

231 lines. Instead, Wakimoto et al. (2006b) determined that mechanically forced, compensating downdrafts

232 on the edge of developing convective storms were responsible for the downward-tilted cold pool

233 baroclinic vortex lines (Fig. 8b). They also note that rainy downdrafts do not develop until the cell is

234 well behind the gust front precluding the scenario envisioned in TW03 from occurring.

\subsection{Upward vortex line tilting}

Like WT03 and TW03, Atkins and St. Laurent (2009b; hereafter ASL09b) also studied quasiidealized simulations of MCSs. ASL09b studied the genesis of mesovortices in their simulations and found substantial differences when compared to TW03 and Wakimoto et al. (2006b). Specifically, while vorticity couplets developed in ASL09b, the cyclonic member formed to the north of the anti-cyclonic member. A vortex arch (e.g., Straka et al. 2007; Markowski et al. 2008) connected the cyclonic and anticyclonic areas of vorticity. ASL09b suggest that a localized outflow maximum behind the system gust front led to a gust front bulge. Enhanced convergence associated with this gust front bulge caused the development of a localized enhancement in the updraft which arched crosswise baroclinically-generated vortex lines and led to the vorticity couplets in the simulation (Fig. 9a). As in TW03, the cyclonic member of the couplet was favored while the anti-cyclonic member weakened (the simulations in ASL09b all included Coriolis forcing). 
ASL09b also found cyclonic-only mesovortices that developed in their simulations. These

249 vortices did not form as part of a vortex-couplet, and instead developed as parcels descended while

250 acquiring baroclinically generated streamwise vorticity (Fig. 9b). This is a similar mechanism to that

251 proposed for low-level mesocyclone formation by Rotunno and Klemp (1985) and Davies-Jones and

252 Brooks (1993). The cyclonic-only mesovortex development generally occurred very early in the

253 simulation and then again late in the simulation once a well-defined rear-inflow jet developed. ASL09b

254 attempt to reconcile the differences in mesovortex-formation conceptual models by performing and 255 idealized simulation of the same case studied in Wakiomto et al (2006b) but found that upward tilting of 256 vortex lines was responsible for the generation of mesovortex couplets in their simulation. Wheatley 257 and Trapp (2008) also simulated the case studied in Wakimoto et al. (2006b) with the WRF model 258 (however, their simulation was less idealized and included environmental heterogeneity) and found 259 downward tilting of vortex lines led to the formation of vortex couplets (Fig. 10). As such, reconciling 260 the differences in the ASL09b and TW03 conceptual models is not possible without a large degree of 261 speculation. Instead, we note that both models implicate the tilting of crosswise baroclinically 262 generated vorticity to form vortex couplets. It is also worth noting that both conceptual models for 263 mesovortex genesis conclude that shearing instability is not important in the generation of 264 mesovortices. Earlier observational studies had speculated that shearing instability may play a role in 265 the development of mesovortices (e.g., Przybylinski 1995, Funk et al. 1999, Trapp et al. 1999). These 266 numerical studies do not support that assertion. However, Wheatley and Trapp (2008) found that in a

267 strongly-forced, cool-season QLCS, system-scale tilting of extremely large environmental vorticity led to 268 the development of a vortex sheet. Shearing instability in this vortex sheet was implicated in the 269 development of mesovortices in this case. 
Further complicating the conceptualization of the formation of mesovortices, a recent study by Xu

273 et al. (2015b) has implicated the importance of surface drag in the generation of mesovortices. Both

274 TW03 and ASL09b neglected surface drag in their quasi-idealized simulations of mesovortices. In

275 contrast, Xu et al. (2015a) simulated the 8 May 2009 super-derecho (e.g., Coniglio et al. 2010; Weisman

276 et al. 2013) at 800-m grid spacing, starting from an initial condition that assimilated all available

277 observations. This real data simulation employed a full physics package that included a surface drag

278 parameterization. Through circulation (e.g., Rotunno and Klemp 1985) and trajectory analysis, Xu et al.

279 (2015b) found that surface drag played a significant role in generating vorticity that fed into the 280 developing mesovortices (Fig. 11). The simulation examined in Schenkman et al. (2012) also showed

281 that surface drag played a role in mesovortex dynamics, but in their study baroclinic vorticity generation

282 and subsequent arching (as in ASL09b) were found to be directly responsible for mesovortex rotation.

283 Owing to the lack of more simulation studies that include surface drag, it is not possible at this time to

284 assess the generality of the conclusions presented in Xu et al. (2015b). Additionally, the fact that free-

285 slip simulations (e.g., TW03, ASL09b) produced mesovortices implies that surface drag is not necessary

286 to simulate mesovortex genesis. It is also worth noting that rather than explicitly calculating the 287 contribution of surface drag to circulation and vorticity budgets, Xu et al. (2015b) treat frictionally 288 generated circulation and vorticity as the residual in their calculations. More simulations that include 289 surface drag and explicitly calculate its contribution to vorticity and circulation in mesovortices are 290 required to determine if frictionally generated vorticity always plays an important role in mesovortex 291 genesis. A recent real-data simulation study by Schenkman et al. (2014) also pointed out the importance 292 of frictionally generated horizontal vorticity as a source of rotation for tornadogenesis within a supercell 293 storm, so the potential importance of frictional vorticity generation for the intensification of low-level 294 vortices is definitely worth investigating. 


\section{Forecasting mesovortices}

Despite the differences in mesovortex genesis conceptualizations, case studies of convectionresolving numerical simulations show promising results for the accurate prediction of bow-echoes and associated mesovortices (Wheatley and Trapp 2008; Schenkman et al. 2011b, a; Snook et al. 2011; Schenkman et al. 2012; Snook et al. 2012; Wheatley et al. 2012; Weisman et al. 2013; Snook et al. 2015; Xu et al. 2015a, 2015b). In this section, two such case studies are reviewed in-depth: The 8-9 May 2007 Oklahoma tornadic convective system (e.g., Schenkman et al. 2011a,b) and the 8 May 2009 'superderecho' (Weisman et al. 2013, Xu et al. 2015a,b).

\subsection{The 8-9 May 2007 tornadic convective system.}

On 8 May 2007, a large MCS formed over eastern NM and west TX. The MCS persisted throughout the day and upon entering west-central Oklahoma that night began producing tornadic and non-tornadic mesovortices. The mesovortices were generally located in the comma-echo portion of the MCS (e.g., Fujita 1978; Pfost and Gerard 1997). Tornadic mesovortices were found to be longer-lived than non-tornadic mesovortices (Schenkman et al. 2011b) in agreement with Atkins et al. (2004) and Atkins et al. (2005). Schenkman et al. $(2011 a, b)$ used the Advanced Regional Prediction system (ARPS; e.g., Xue et al. 2003) 3DVAR with a cloud analysis package (e.g., Hu et al. 2006) to assimilate multiple sources of data from this case. Assimilated data included conventional surface and upper air observations, WSR-88D reflectivity and velocity data, and radar data from the experimental Collaborative and Adaptive Sensing of the Atmosphere's IP-I network (CASA; e.g., McLaughlin et al. 2009). The CASA IP-I network was designed to fill the gap in low-level radar coverage $(<1 \mathrm{~km} \mathrm{AGL})$ in southwest Oklahoma between the Twin Lakes (KTLX )and Frederick (KFDR) WSR-88Ds.

Schenkman et al. (2011a) found that accurate short term forecasts (up to $3 \mathrm{~h}$ ) of the overall convective system and line-end vortex could be produced by the ARPS model when radar data were 
assimilated, using 2-km grid spacing (Fig. 12). The assimilation of CASA data had a small positive impact on the forecast accuracy of the line-end vortex track in Schenkman et al. (2011a). Encouraged by the results of the system-scale simulation, Schenkman et al. (2011b) assimilated the same data sources at 400-m grid spacing with the goal of investigating the impacts on the forecasts of mesovortices in the case. At this resolution, low-level radial wind data assimilation from CASA had a substantial impact on the analysis and forecast of the sub-system scale features. Specifically, low-level wind data assimilation led to a more accurate depiction of the near-storm low-level shear and gust front position during the analysis period (not shown). During the forecast period experiments that assimilated low-level winds produced much more accurate 1-2 $\mathrm{h}$ forecasts of the location, intensity, and duration of one of the observed long-lived mesovortices associated with the QLCS (Fig. 13). Experiments that did not assimilate low-level wind data produced numerous weak mesovortices that developed too early in the simulation and rapidly dissipated (Fig. 13e).

Schenkman et al. (2012) further nested a grid with a 100-m spacing within one of the 400-m grid spacing forecasts from Schenkman et al. (2011b). As discussed in section 2, this simulation produced a weak tornado-like vortex in association with the long-lived mesovortex forecasted. In the observed case, this long-lived mesovortex also produced a weak tornado in a similar location as in the simulated experiment. Though the tornado-like vortex occurred $20 \mathrm{~min}$ too early in the $100-\mathrm{m}$ forecast, the similarities to the evolution of the observed tornadic mesovortex are encouraging for providing 337 significantly enhanced lead-time for mesovortex tornadoes. This enhanced lead time is necessary for the National Weather Service's proposed shift to a warn-on-forecast paradigm, where warnings for 339 hazards are issued based on high-resolution numerical forecasts rather than upon detection (e.g., 340 Stensrud et al. 2009; Stensrud et al. 2012).

Snook et al. (2011, 2012, 2015) also examined the same 8-9 May 2007 MCS but used the 
Xue et al. (2006), and produced probabilistic instead of deterministic forecasts. Like Schenkman et al. $(2011 a, b)$, Snook et al. $(2012,2015)$ obtained accurate forecasts of track and timing of the line-end vortex and an associated long-lived mesovortex. They also demonstrated potential skills in probabilistic forecasting of tornado-like vortices within a high-resolution numerical model.

Taken as a whole, the results of this multi-scale case study suggest that it may be possible to accurately forecast the development of strong, long-lived mesovortices with up to 2 hours of lead time given adequate low-level observations. This result is reinforced by the fact that accurate forecasts were produced using two distinct data assimilation methods as well as in both a deterministic and probabilistic framework.

\subsection{The 8 May 2009 Super Derecho}

On 8 May 2009, an unusually intense MCS produced widespread wind damage and multiple tornadoes across Kansas, southern Missouri, and southern Illinois (Fig. 14a). Convective initiation occurred along the eastern slope of the Rocky Mountains in Colorado. The system intensified as it encountered unusually strong and deep low-level jet in Kansas and Missouri (Coniglio et al. 2010). As the MCS matured a very intense warm-core mesolow formed at the northern tip of the bow-echo. Weisman et al. (2013) examined a real-time 3-km grid spacing simulation of this system produced with the Advanced Research core of the Weather Research Forecasting model (WRF-ARW; Skamarock and Klemp 2008). This simulation accurately captured the development of many of the key features of the observed event, including the mesolow, up to $24 \mathrm{~h}$ in advance (Fig. 14b). However, Weisman et al. (2013) note that while many mesovortices were observed in the actual event, they were not present in the WRF-ARW simulation likely owing to insufficient resolution.

Xu et al. (2015a) used Doppler radar observations to examine the mesovortices observed during the mature phase of the 8 May 2009 super derecho in more detail. They identify 9 mesovortices (Fig. 
14c), 5 of which were tornadic. All tornadic mesovortices were located to the north of the bow echo

368 apex. Xu et al. (2015a) also generated and examined a 0.8-km grid interval simulation of the super 369 derecho, that was nested within a 4-km CONUS-domain realtime forecast from the Center for Analysis 370 and Prediction of Storms (CAPS)_storm-scale ensemble forecast (SSEF) runs (Xue et al. 2009). The 371 simulation in Xu et al. (2015a) also produced 9 mesovortices (Fig. 14d) during the period they examined 372 (that spanned from 1400 to 1640 UTC with the initial condition being at 0000 UTC). Though there is not 373 a one-to-one correspondence between simulated and observed mesovortices, the simulated 374 mesovortices from Xu et al. (2015a) generally follow a similar path and are in a similar MCS-relative 375 location as the observed mesovortices (Fig. 14c,d). Analysis of these mesovortices show that high winds 376 were generally associated with the mesovortices near the bow echo apex. In agreement with ASL09a 377 and Wakimoto et al (2006b), these high winds were caused by the superposition of the rear-inflow jet 378 and the mesovortex flow.

The reasonably skillful mesoscale and storm-scale forecasts of the 8 May 2009 super derecho present a possible blueprint for operational forecasting of bow-echo mesovortices in a warn on forecast context. More specifically, a convection-resolving simulation of a bow-echo could be used to initialize a 382 short-term higher-resolution nested simulation capable of resolving mesovortices. While a one-to-one 383 correspondence of model forecasted and observed mesovortices is highly unlikely beyond the typical life 384 cycle of mesovortices, these mesovortex-resolving simulations could be used to alert operational 385 forecasters to the potential for long-lived mesovortices, and thus, damaging winds and tornadoes. When 386 an ensemble of such forecasts is produced, probabilistic information could also be provided. Beyond the 387 warn on forecast time frame, the results of the 8 May 2009 forecasts suggest it may be possible to have 388 up to 24 hours of lead time for the potential for damaging mesovortices given a successful larger scale 389 forecast. 


\section{A look ahead}

Great strides have been made in the understanding of mesovortices and their association with high

392 winds and tornadoes in QLCSs. Interestingly, however, the dynamics behind mesovortex generation

remains an open research problem. At least five hypotheses exist that explain mesovortex genesis. In the first three hypotheses (i-iii), vortex couplets are formed as storm-generated (baroclinic) vortex lines are either depressed downward by (i) rainy downdrafts (e.g., TW03), or (ii) mechanically forced downdrafts (Wakimoto et al. 2006b), or are arched upward by (iii) a localized updraft enhancement

397 (ASL09b, Schenkman et al. 2012). In contrast, the other two hypothesis (iv-v) explain the development of cyclonic-only mesovortices via the tilting of (iv) baroclinic vorticity as parcels descend parallel to the convective gust front (ASL09b) or (v) frictionally generated vorticity as parcels ascend at the gust front

400 (Xu et al. 2015b). Future work should focus on obtaining high-quality observational data sets of MCSs 401 that spawn mesovortices in order to initialize high-resolution model simulations through advanced data assimilation methods (e.g., Schenkman et al. 2011a,b; Snook et al 2012,2015). Vorticity calculations 403 along trajectories combined with circulation analyses should provide the necessary evidence to 404 determine what mesovortex genesis mechanisms are occurring in the simulations. Inclusion of a surface 405 drag parameterization is imperative in these simulations in order to assess the validity of the mesovortex genesis mechanism proposed by Xu et al. (2015b). It is also possible that the mesovortex 407 genesis mechanism will vary depending on model parameters. For example, as discussed above, 408 ASL09b used a different configuration of the WRF-ARW to simulate the same case as Wheatley et al. 409 (2008) and found a different mesovortex genesis mechanism. An idealized model parameter study, 410 perhaps including different forecast models, may be necessary to understand the sensitivity of the 411 conclusions on the model and model configurations. opportunities for future research. While it has been shown that tornadic mesovortices tend to be 
414 longer-lived and deeper than non-tornadic mesovortices, the root causes behind this tendency remain

415 relatively unexplored. Specifically, it is unknown why some mesovortices are stronger and longer-lived 416 than other mesovortices within the same system. It is encouraging that case studies of these

417 mesovortex-producing systems have shown promise in forecasting the development of long-lived

418 mesovortices. With the continued increase in computational power, as well as advances in data

419 assimilation techniques and improvement in the accuracy of numerical models, it should be possible to

420 produce more simulations that capture tornado-like processes. Assuming the simulations can accurately

421 portray tornado-like vortices, analysis of these simulations should allow researchers to gain a more

422 fundamental understanding of the dynamical relationship between mesovortices and the tornadoes

423 they spawn. Increased understanding, along with accurate forecast models, may give forecasters the

424 information they need to better anticipate the development of tornadoes in association with

425 mesovortices thus reducing false-alarms and increasing lead-time for tornado warnings in these 426 scenarios.

427 Acknowledgements: This work was primarily supported by NSF grant AGS-0802888. Additional 428 support was provided by the National 973 Fundamental Research Program of China (2013CB430103), 429 and NSF grants AGS-1046171 and AGS-1261776. Helpful comments and suggestions from two 430 anonymous reviewers helped improve this manuscript. 
432

433

434

435

436

437

438

439

440

441

442

443

444

445

446

447

448

449

450

451

452

453

454

455

456

\section{References}

Atkins, N. T., J. M. Arnott, R. W. Przybylinski, R. A. Wolf, and B. D. Ketcham, 2004: Vortex Structure and Evolution within Bow Echoes. Part I: Single-Doppler and Damage Analysis of the 29 June 1998 Derecho. Mon. Wea. Rev., 132, 2224-2242.

Atkins, N. T., C. S. Bouchard, R. W. Przybylinski, R. J. Trapp, and G. Schmocker, 2005: Damaging Surface Wind Mechanisms within the 10 June 2003 Saint Louis Bow Echo during BAMEX. Mon. Wea. Rev., 133, 22752296.

Atkins, N. T. and M. St. Laurent, 2009a: Bow echo mesovortices. Part I: Processes that influence their damaging potential. Mon. Wea. Rev., 137, 1497-1513.

Atkins, N. T. and M. St. Laurent, 2009b: Bow echo mesovortices. Part II: Their genesis. Mon. Wea. Rev., 137, 15141532.

Burgess, D. W. and B. F. Smull, 1990: Doppler radar observations of a bow echo associated with a long-track severe windstorm. 16th Conf. on Severe Local Storms, Kananaskis Park, AB, Canada, Amer. Meteor. Soc., 203-208.

Coniglio, M. C., S. F. Corfidi, and J. S. Kain, 2010: Environment and Early Evolution of the 8 May 2009 DerechoProducing Convective System. Mon. Wea. Rev., 139, 1083-1102.

Davies-Jones, R. P. and H. Brooks, 1993: Mesocyclogenesis from a theoretical perspective. The Tornado: Its Structure, Dynamics, Prediction, and Hazards, C. R. Church, Ed., Amer. Geophys. Union Press, 105-114.

Davis, C., N. Atkins, D. Bartels, L. Bosart, M. Coniglio, G. Bryan, W. Cotton, D. Dowell, B. Jewett, R. Johns, D. Jorgensen, J. Knievel, K. Knupp, W.-C. Lee, G. Mcfarquhar, J. Moore, R. Przybylinski, R. Rauber, B. Smull, R. Trapp, S. Trier, R. Wakimoto, M. Weisman, and C. Ziegler, 2004: The Bow Echo and MCV Experiment: Observations and opportunities. Bull. Amer. Meteor. Soc., 85, 1075-1093.

Forbes, G. S. and R. M. Wakimoto, 1983: A concentrated outbreak of tornadoes, downbursts and microbursts, and implications regarding vortex classification. Mon. Wea. Rev., 111, 220-235.

Fujita, T. T., 1978: Manual of downburst identification for project Nimrod. Satellite and Mesometeorology Res. Pap. 156. Dept. of Geophysical Science, University of Chicago, 104pp [NTISPB-286048]. 
Fujita, T. T., 1979: Objective, operation, and results of Project NIMROD. 11th Conf. on Severe Local Storms, Kansas City, MO, Amer. Meteor. Soc., 259-266.

Fujita, T. T., 1981: Tornadoes and downbursts in the context of generalized planetary scales. J. Atmos. Sci., 38, 1511-1534.

Fujita, T. T. and R. M. Wakimoto, 1981: Five scales of airflow associated with a series of downbursts of 16 July 1980. Mon. Wea. Rev., 109, 1438-1456.

Funk, T., K. Darmofal, J. Kirkpatrick, V. DeWald, R. Przbylinski, G. Schmocker, and Y.-J. Lin, 1999: Storm reflectivity

Jorgensen, D. P. and B. F. Smull, 1993: Mesovortex circulations seen by air-borne Doppler radar within a bow-echo

McLaughlin, D., D. Pepyne, V. Chandrasekar, B. Philips, J. Kurose, M. Zink, K. Droegemeier, S. Cruz-Pol, F. Junyent, J.

Johnston, E. C., 1981: Mesoscale vorticity centers induced by mesoscale convective complexes, M. S., Dept. of Meteor., University of Wisconsin, 54 pp. mesoscale convective system. Bull. Amer. Meteor. Soc., 74, 2146-2157.

Klemp, J. B. and R. B. Wilhelmson, 1978: The simulation of three-dimensional convective storm dynamics. J. Atmos. Sci., 35, 1070-1096.

Klimowski, B. A., 1994: Initiation and development of rear inflow within the 28-29 June 1989 North Dakota mesoconvective system. Mon. Weal Rev., 122, 765-779.

Markowski, P., E. Rasmussen, J. Straka, R. Davies-Jones, Y. Richardson, and R. J. Trapp, 2008: Vortex lines within low-level mesocyclones obtained from pseudo-dual-doppler radar observations. Mon Weather Rev, 136, 3513-3535. Brotzge, D. Westbrook, N. Bharadwaj, Y. Wang, E. Lyons, K. Hondl, Y. Liu, E. Knapp, M. Xue, A. Hopf, K. Kloesel, A. DeFonzo, P. Kollias, K. Brewster, R. Contreras, B. Dolan, T. Djaferis, E. Insanic, S. Frasier, and F. 
Carr, 2009: Short-wavelength technology and the potential for distributed networks of small radar systems. Bull. Amer. Meteor. Soc., 90, 1797-1817.

Menard, R. D. and J. M. Fritsch, 1989: A mesoscale convective complex-generated inertially stable warm core vortex. Mon. Wea. Rev., 117, 1237-1260.

Orlanski, I., 1975: A rational subdivision of scales for atmospheric processes. Bull. Amer. Meteor. Soc., 56, 527-530.

Pfost, R. L. and A. E. Gerard, 1997: "Bookend vortex"-induced tornadoes along the Natchez Trace. Wea. Forecasting, 12, 572-580.

Przbylinski, R., G. Schmocker, and Y.-J. Lin, 2000: A study of storm and vortex morphology during the "intensifying stage" of severe wind mesoscale convective systems. 20th Conf. on Severe Local Storms, Amer. Meteor. Soc., $173-176$.

Przybylinski, R. W., 1995: The bow echo. Observations, numerical simulations, and severe weather detection methods. Wea. Forecasting, 10, 203-218.

Rotunno, R. and J. B. Klemp, 1985: On the rotation and propagation of simulated supercell thunderstorms. J. Atmos. Sci., 42, 271-292.

Schenkman, A., M. Xue, and M. Hu, 2014: Tornadogenesis within numerically simulated 8 May 2003 Oklahoma City tornadic supercell storm. J. Atmos. Sci., 71, 130-154.

Schenkman, A., M. Xue, and A. Shapiro, 2012: Tornadogenesis in a simulated mesovortex within a mesoscale convective system. J. Atmos. Sci., 69, 3372-3390.

Schenkman, A., M. Xue, A. Shapiro, K. Brewster, and J. Gao, 2011a: The analysis and prediction of the 8-9 May 2007 Oklahoma tornadic mesoscale convective system by assimilating WSR-88D and CASA radar data using 3DVAR. Mon. Wea. Rev., 139, 224-246.

Schenkman, A., M. Xue, A. Shapiro, K. Brewster, and J. Gao, 2011b: Impact of CASA radar and Oklahoma mesonet 506 data assimilation on the analysis and prediction of tornadic mesovortices in a MCS. Mon. Wea. Rev., 139, $3422-3445$.

Skamarock, W. C. and J. B. Klemp, 2008: A time-split nonhydrostatic atmospheric model for weather research and forecasting applications. J. Comput. Phys., 227, 3465-3485. 
Skamarock, W. C., M. L. Weisman, and J. B. Klemp, 1994: Three-dimensional evolution of simulated long-lived squall lines. J. Atmos. Sci., 51, 2563-2584.

Smull, B. F. and R. A. Houze, Jr., 1987: Rear inflow in squall lines with trailing stratiform precipitation. Mon. Wea. Rev., 115, 2869-2889.

Snook, N., M. Xue, and J. Jung, 2011: Analysis of a tornadic meoscale convective vortex based on ensemble Kalman filter assimilation of CASA X-band and WSR-88D radar data. Mon. Wea. Rev., 139, 3446-3468.

Snook, N., M. Xue, and Y. Jung, 2012: Ensemble probabilistic forecasts of a tornadic mesoscale convective system from ensemble Kalman filter analyses using WSR-88D and CASA radar data. Mon. Wea. Rev., 140, 21262146.

Snook, N., M. Xue, and Y. Jung, 2015: Multiscale EnKF assimilation of radar and conventional observations and ensemble forecasting for a tornadic mesoscale convective system. Mon. Wea. Rev., 143, 1035-1057.

Stensrud, D. J., L. J. Wicker, M. Xue, D. Dawson, N. Yussouf, D. Wheatley, T. E. Thompson, N. A. Snook, T. M. Smith, A. D. Schenkman, C. K. Potvin, E. R. Mansell, T. Lei, K. M. Kuhlman, Y. Jung, T. A. Jones, J. Gao, M. C. Coniglio, H. E. Brooks, and K. A. Brewster, 2012: Progress and challenges with Warn-on-Forecast. Atmos. Res., In press.

Stensrud, D. J., M. Xue, L. J. Wicker, K. E. Kelleher, M. P. Foster, J. T. Schaefer, R. S. Schneider, S. G. Benjamin, S. S. Weygandt, J. T. Ferree, and J. P. Tuell, 2009: Convective-scale Warn on Forecast System: A Vision for 2020. Bull. Am. Meteor. Soc., 90, 1487-1499.

Straka, J., E. Rasmussen, R. Davies-Jones, and P. Markowski, 2007: An observational and idealized numerical examination of low-level counter-rotating vortices toward the rear flank of supercells. Electron. J. Severe Storms Meteor, 2, 1-22.

Tong, M. and M. Xue, 2005: Ensemble Kalman filter assimilation of Doppler radar data with a compressible nonhydrostatic model: OSS Experiments. Mon. Wea. Rev., 133, 1789-1807.

Trapp, R. J., S. A. Tessendorf, E. S. Godfrey, and H. Brooks, 1999: Descending and nondescending tornadic vortex signatures detected by WSR-88Ds. Wea. Forecasting, 14, 625-639.

Trapp, R. J., S. A. Tessendorf, E. S. Godfrey, and H. E. Brooks, 2005: Tornadoes from squall lines and bow echoes. Part I: Climatological distribution. Wea. Forecasting, 20, 23-34. 
Trapp, R. J. and M. L. Weisman, 2003: Low-Level mesovortices within squall lines and bow echoes. Part II: Their genesis and implications. Mon. Wea. Rev., 131, 2804-2823.

Wakimoto, R. M., H. V. Murphey, C. A. Davis, and N. T. Atkins, 2006a: High winds generated by bow echoes. Part II: The relationship between the mesovortices and damaging straight-line winds. Mon. Wea. Rev., 134, 28132829.

Wakimoto, R. M., H. V. Murphey, A. Nester, D. P. Jorgensen, and N. T. Atkins, 2006b: High winds generated by bow echoes. Part I: Overview of the Omaha bow echo 5 July 2003 storm during BAMEX. Mon. Wea. Rev., 134, 2793-2812.

Weisman, M., C. Evans, and L. Bosart, 2013: The 8 May 2009 superderecho: Analysis of a real-time explicit convective forecast. Wea. Forecasting, 28, 863-892.

Weisman, M. L., 1992: The role of convectively generated rear-inflow jets in the evolution of long-lived mesoconvective systems. J. Atmos. Sci., 49, 1826-1847.

Weisman, M. L., 1993: The genesis of severe long-lived bow-echoes. J. Atmos. Sci., 50, 645-670.

Weisman, M. L. and C. A. Davis, 1998: Mechanisms for the generation of mesoscale vortices within quasi-linear convective systems. J. Atmos. Sci., 55, 2603-2622.

Weisman, M. L. and R. J. Trapp, 2003: Low-Level Mesovortices within Squall Lines and Bow Echoes. Part I: Overview and Dependence on Environmental Shear. Mon. Wea. Rev., 131, 2779-2803.

Wheatley, D. M., D. J. Stensrud, D. Dowell, and N. Yussouf, 2012: Application of a WRF mesoscale data assimilation system to springtime severe weather events 2007-09. Mon. Wea. Rev., 140, 1539-1557.

Wheatley, D. M. and R. J. Trapp, 2008: The effect of mesoscale heterogeneity on the genesis and structure of mesovortices within quasi-linear convective systems. Mon. Wea. Rev., 136, 4220-4241.

Wheatley, D. M., R. J. Trapp, and N. T. Atkins, 2006: Radar and Damage Analysis of Severe Bow Echoes Observed during BAMEX. Mon. Wea. Rev., 134, 791-806.

Wolf, P. L., 1998: WSR-88D radar depiction of supercell-bow echo interaction: Unexpected evolution of a large,tornadic,comma-shaped supercell of eastern Oklahoma. Wea. Forecasting, 13, 492-504. 
Xu, X., M. Xue, and Y. Wang, 2015a: Mesovortices within the 8 May 2009 bow echo over central US: Analyses of the characteristics and evolution based on Doppler radar observations and a high-resolution model simulation. . Mon. Wea. Rev., 143, 2266-2290.

$\mathrm{Xu}, \mathrm{X} ., \mathrm{M}$. Xue, and Y. Wang, 2015b: The genesis of mesovortices within a real-data simulation of a bow echo system. J. Atmos. Sci., 72, 1963-1986.

567 Xue, M., F. Kong, K. W. Thomas, J. Gao, Y. Wang, K. Brewster, K. K. Droegemeier, X. Wang, J. Kain, S. Weiss, D. Bright, M. Coniglio, and J. Du, 2009: CAPS realtime multi-model convection-allowing ensemble and 1-km convection-resolving forecasts for the NOAA Hazardous Weather Testbed 2009 Spring Experiment. 23nd Conf. Wea. Anal. Forecasting/19th Conf. Num. Wea. Pred., Omaha, NB, Amer. Meteor. Soc., Paper 16A.2.

571 Xue, M., M. Tong, and K. K. Droegemeier, 2006: An OSSE framework based on the ensemble square-root Kalman 572 filter for evaluating impact of data from radar networks on thunderstorm analysis and forecast. J. Atmos. Ocean Tech., 23, 46-66.

574 Xue, M., D.-H. Wang, J.-D. Gao, K. Brewster, and K. K. Droegemeier, 2003: The Advanced Regional Prediction 575 System (ARPS), storm-scale numerical weather prediction and data assimilation. Meteor. Atmos. Phy., 82, 139-170. 


\section{List of Figures}

Fig. 1. Radar morphology of bow echoes that produce strong and extensive downbursts, labeled DB. [From Fujita (1978)]

Fig. 2. Schematic representation of an idealized two-dimensional vortex couplet. Strong flow is induced between the vortices. The shading represents regions of constant vorticity. Dashed contours mark the area of a negative pressure perturbation field associated with the flow pattern. The ' $\mathrm{L}$ ' marks the location of lowest pressure. [Adapted from Weisman (1993)]

Fig. 3. Three-dimensional depiction of vortex lines (denoted by the thick solid lines) arching over a simulated cold pool (<- $1 \mathrm{~K}$, shaded). Vectors represent the surface wind flow. [From Weisman and Davis (1998)]

Fig. 4. Five scales of downburst damage patterns identified via detailed post-storm damage surveys. Note that the definition of scales differs from those of Orlanski (1975). [From Fujita and Wakimoto (1981)]

Fig. 5. Doppler wind synthesis at 0538:00-00548:26 UTC 5 July 2003 at $400 \mathrm{~m}$ AGL for a mesovortex associated with damaging winds. In (a) the total analyzed wind field is plotted. In (b), the circulation associated with the mesovortex is removed. Wind $>35 \mathrm{~m} \mathrm{~s}^{-1}$ are shaded in gray. Black and gray lines are vertical vorticity and isotachos, respectively. [From Wakimoto et al (2006b)].

Fig. 6. Two schematic depictions of the relationship between mesovortices and damaging winds in bow echoes. (Top) From Trapp and Weisman (2003), the red circles represent mesovortices, the red blob in the vertical plane represents vertical vorticity. The downward-directed PGF (blue arrow) acts to fracture the updraft of the convective system. The gray stippled area shows severe winds associated with the mesovortex and descending RIJ. (Bottom) From Atkins and St. 
Laurent (2009a). The dark shading shows where damaging winds are found as a result of the superposition of the RIJ and the mesovortex flow.

604

605

Fig. 7. Schematic of four-stage process leading up to genesis of a tornado-like vortex (TLV) associated with a mesovortex from Schenkman et al. (2012). Vertical vorticity couplet development is depicted in (I). (II) shows the development of a dominant cyclonic mesovortex and associated development of the frictionally-generated horizontal vorticity. (III) Illustrates the development of the rotor. TLV genesis is shown in (IV). The cyan shading represents the cold pool. The dark blue shading represents enhanced cold air within the cold pool bulge. Black arrows represent the surface flow trajectories. The orange arrows represent trajectories which enter the main updraft. The purple arrow in (III) and (IV) marks the horizontal rotor axis. The magenta arrows represent parcel trajectories that enter the rotor. Light gray vectors are idealized vortex lines. The ' $M$ ' represents the location of the mesovortex. The dotted curves in (II) and (III) mark the location of the enhanced westerly momentum associated with the dissipation of an mesovortex. The ' $v$ ' behind the outflow surge from the initial mesovortex in (III) marks the location of the small area of vertical vorticity moving through the rotor. The ' $T$ ' in (IV) marks the location of the TLV.

Fig. 8. Two conceptual models of the development of vorticity couplets via downward tilting of vortex lines. (a) Early stage conceptual model from Trapp and Weisman (2003), a rainy downdraft tilts baroclinically-generated vortex lines (black lines) downward to create cyclonic (red shading and lines) and anti-cyclonic (blue shading and lines) vertical vorticity. The green boundary represents the system gust front. (b) From Wakimoto et al. (2006b), downward tilting of vortex lines (tube at the edge of the cold pool) by mechanically forced downdrafts (downward pointing white arrows). This mechanical tilting of vortex lines results in a vortex couplet with the same orientation as that of (a). 
Fig. 9. Two Schematic for mesovortexgenesis from Atkins and St. Laurent (2009b). In (A), systemgenerated baroclinic vorticity (gold) is tilted upward by an updraft (red) at the leading edge of the cold pool (black). A vortex couplet (green) straddles the downdraft (blue) and updraft. In (B), a cyclonic-only mesovortex is generated by vorticity tilting in a downdraft along the gust front and subsequent rising motion.

Fig. 10. Simulated vorticity couplet straddling a low-level downdraft at $400 \mathrm{~m} \mathrm{AGL}$. Cyclonic vorticity (solid black lines) is south of anti-cyclonic vorticity (dash black lines). Vertical velocity is shaded $\left(\mathrm{cm} \mathrm{s}^{-1}\right)$. Light gray lines are potential temperature isotherms. [From Wheatley and Trapp (2008)].

Fig. 11. Schematic from Xu et al. (2015b) showing mesovortexgenesis near the apex of a large bow echo. Red lines denote vortex lines. The mesovortex location is marked by the curved purple arrow. A material circuit enclosing the mesovortex is marked in green and shaded in grey.

Fig. 12. Reflectivity at grid level 7 ( 1 km AGL) at 0450 UTC 9 May 2007 (a) observed radar mosaic and (b) $2 \mathrm{hr} 50$ min simulation that assimilated data from the WSR-88D and CASA radars. 'L' marks the approximate location of the observed line-end vortex. The vectors and contours in (b) are the horizontal wind and vertical vorticity, respectively. [Adapted from Schenkman et al. (2011a)].

Fig. 13. (a) Observed radar radial velocity observed by the KOKC TDWR at 0340 UTC 9 May 2007. Simulated radar radial velocity from the KOKC TDWR at 340 UTC 9 May 2007 from (b) experiments that assimilated radial velocity from CASA and (c) experiments that only assimilated WSR-88D data. The panels on the right plot observed mesovortex tracks (dashed line) and simulated mesovortex tracks from (d) experiments that assimilated CASA radial velocity data and (e) those that assimilated WSR-88D data only. [Adapated from Schenkman et al. (2011b)]. 
649 Fig. 14. (a) Observed reflectivity from KPAH at 1756 UTC 8 May 2009. (b) Simulated reflectivity at 1545 650 UTC 8 May 009. [From Weisman et al. (2013)]. (c) Observed reflectivity (grayscale shading) and 651 mesovortex tracks and (d) simulated mesovortex tracks and reflectivity [Adapted from Xu et al. (2015a)]. The color shading represents absolute velocity azimuthal shear in (c) and vertical vorticity in (d). Blue triangles in (c) are locations of reported tornadoes. The black star in (c) is the location of $\mathrm{KPAH}$.

655 


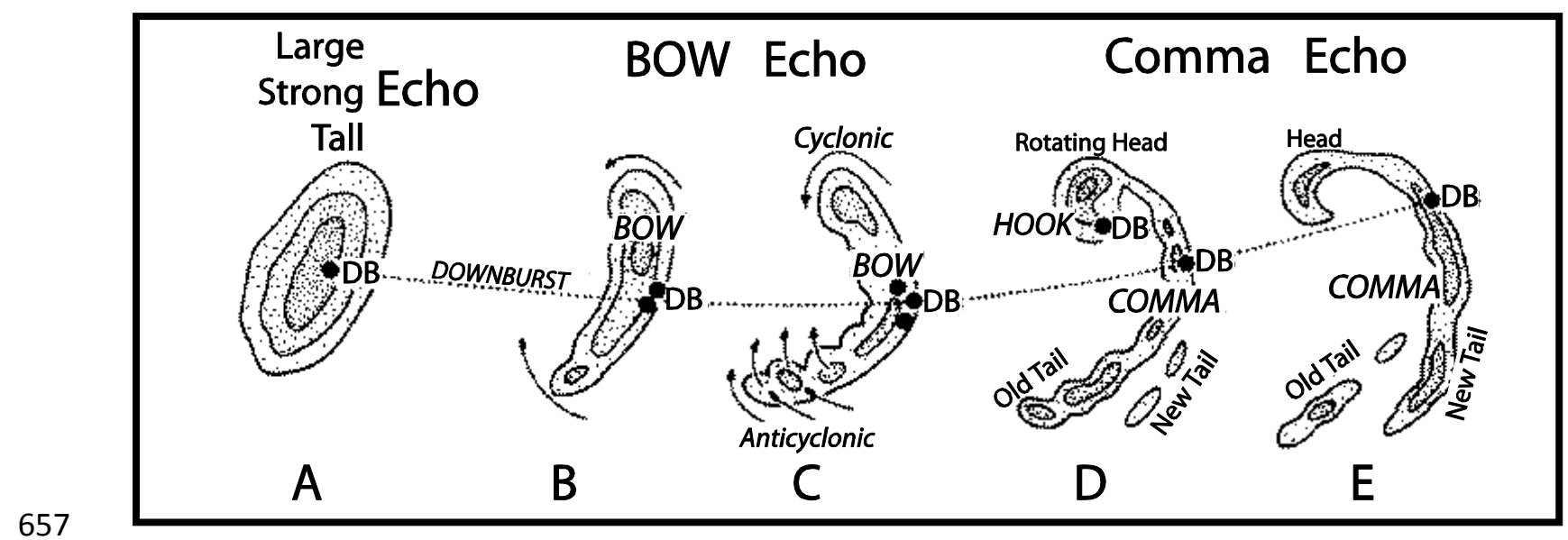

658 Fig. 1. Radar morphology of bow echoes that produce strong and extensive downbursts, labeled DB. [From Fujita 659 (1978)] 


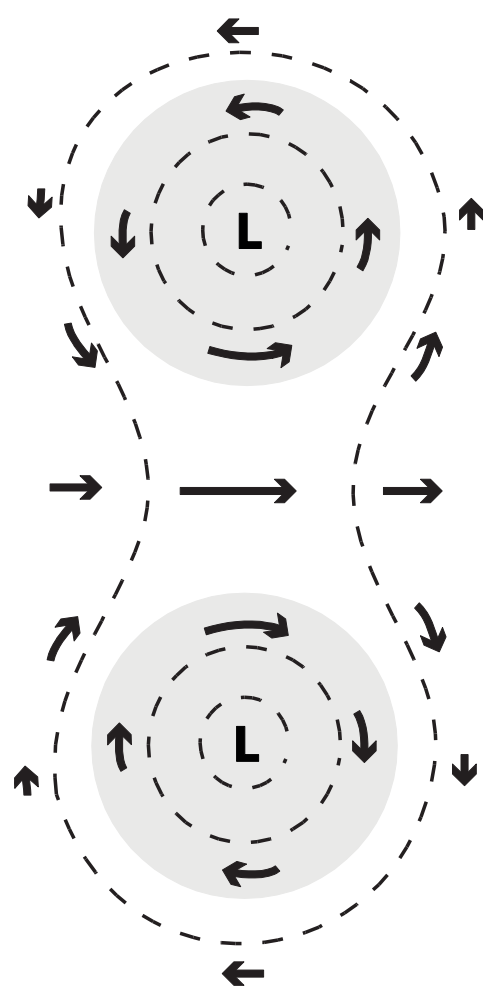

664 Fig. 2. Schematic representation of an idealized two-dimensional vortex couplet. Strong flow is induced between the vortices. The shading represents regions of constant vorticity. Dashed contours mark the area of a negative pressure perturbation field associated with the flow pattern. The ' $L$ ' marks the location of lowest pressure. 


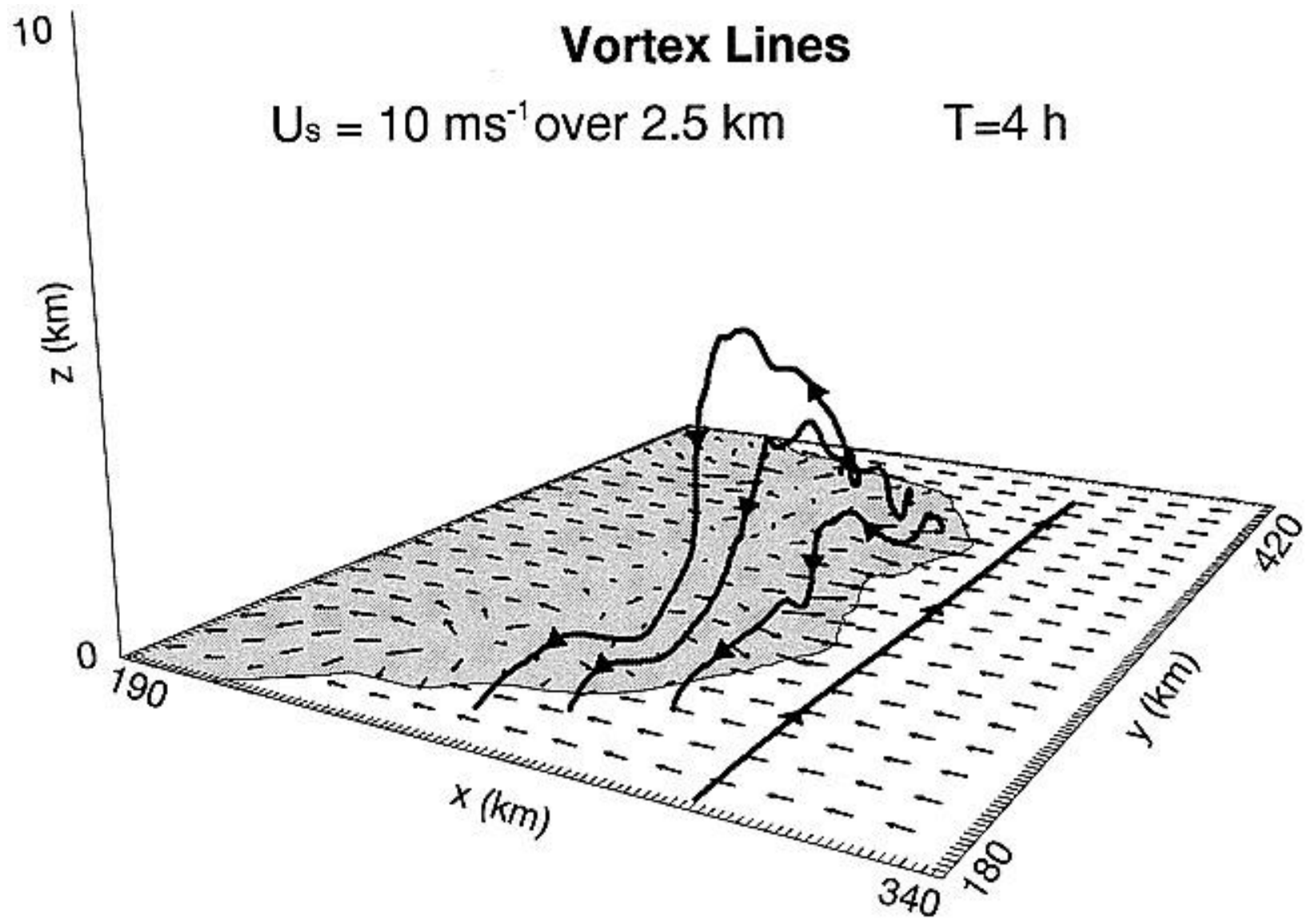

670 Fig. 3. Three-dimensional depiction of vortex lines (denoted by the thick solid lines) arching over a simulated cold 671 pool (<- $1 \mathrm{~K}$, shaded). Vectors represent the surface wind flow. [From Weisman and Davis (1998)] 


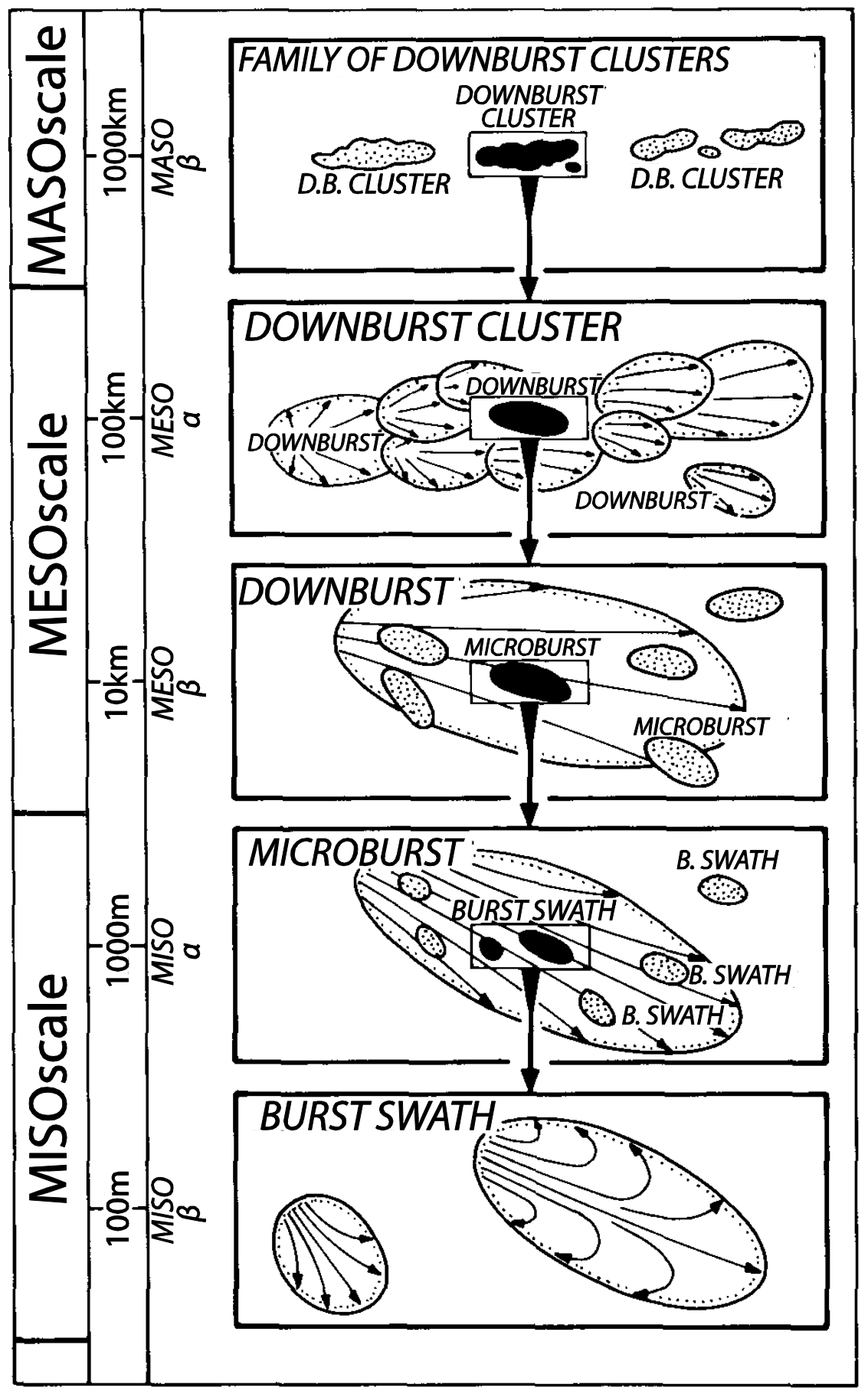

674 Fig. 4. Five scales of downburst damage patterns identified via detailed post-storm damage surveys. Note that the 675 definition of scales differs from those of Orlanski (1975). [From Fujita and Wakimoto (1981)] 

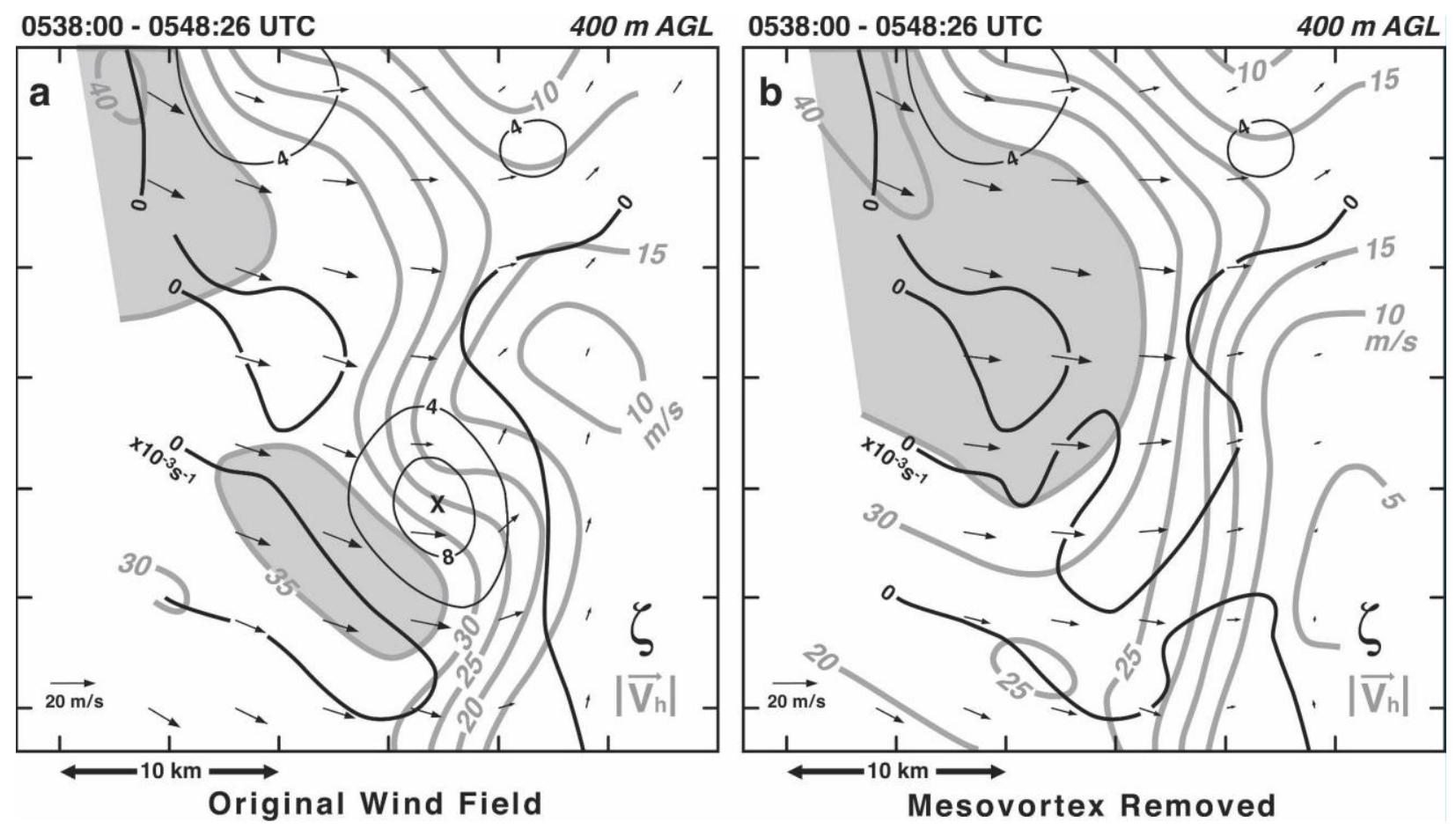

Fig. 5. Doppler wind synthesis at 0538:00-00548:26 UTC 5 July 2003 at $400 \mathrm{~m}$ AGL for a mesovortex associated with damaging winds. In (a) the total analyzed wind field is plotted. In (b), the circulation associated with the mesovortex is removed. Wind $>35 \mathrm{~m} \mathrm{~s}^{-1}$ are shaded in gray. Black and gray lines are vertical vorticity and isotachos, respectively. [From Wakimoto et al (2006b)]. 


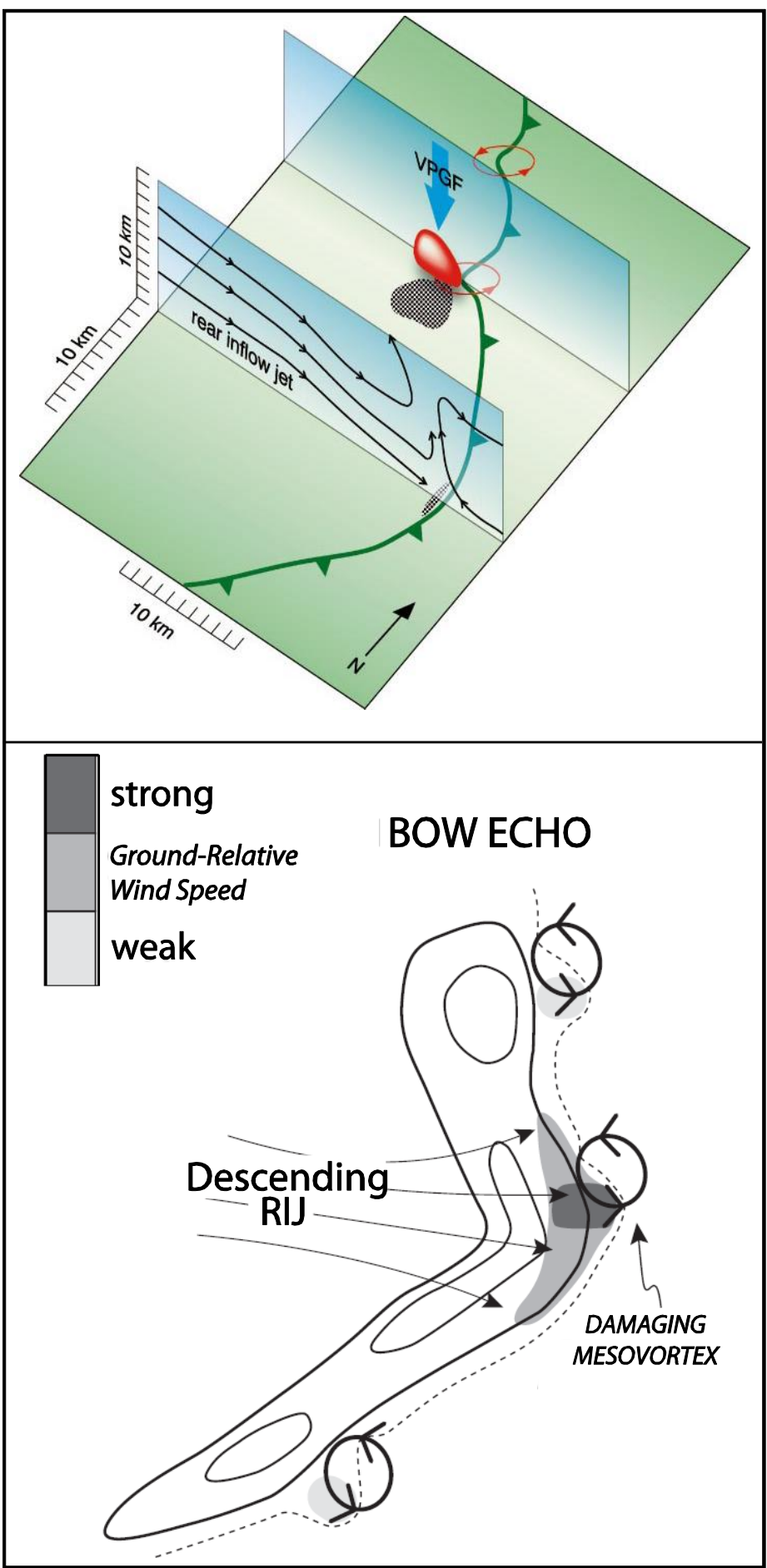

Fig. 6. Two schematic depictions of the relationship between mesovortices and damaging winds in bow echoes. (Top) From Trapp and Weisman (2003), the red circles represent mesovortices, the red blob in the vertical plane represents vertical vorticity. The downward-directed PGF (blue arrow) acts to fracture the updraft of the convective system. The gray stippled area shows severe winds associated with the mesovortex and descending RIJ. (Bottom) From Atkins and St. Laurent (2009a). The dark shading shows where damaging winds are found as a result of the superposition of the RIJ and the mesovortex flow. 

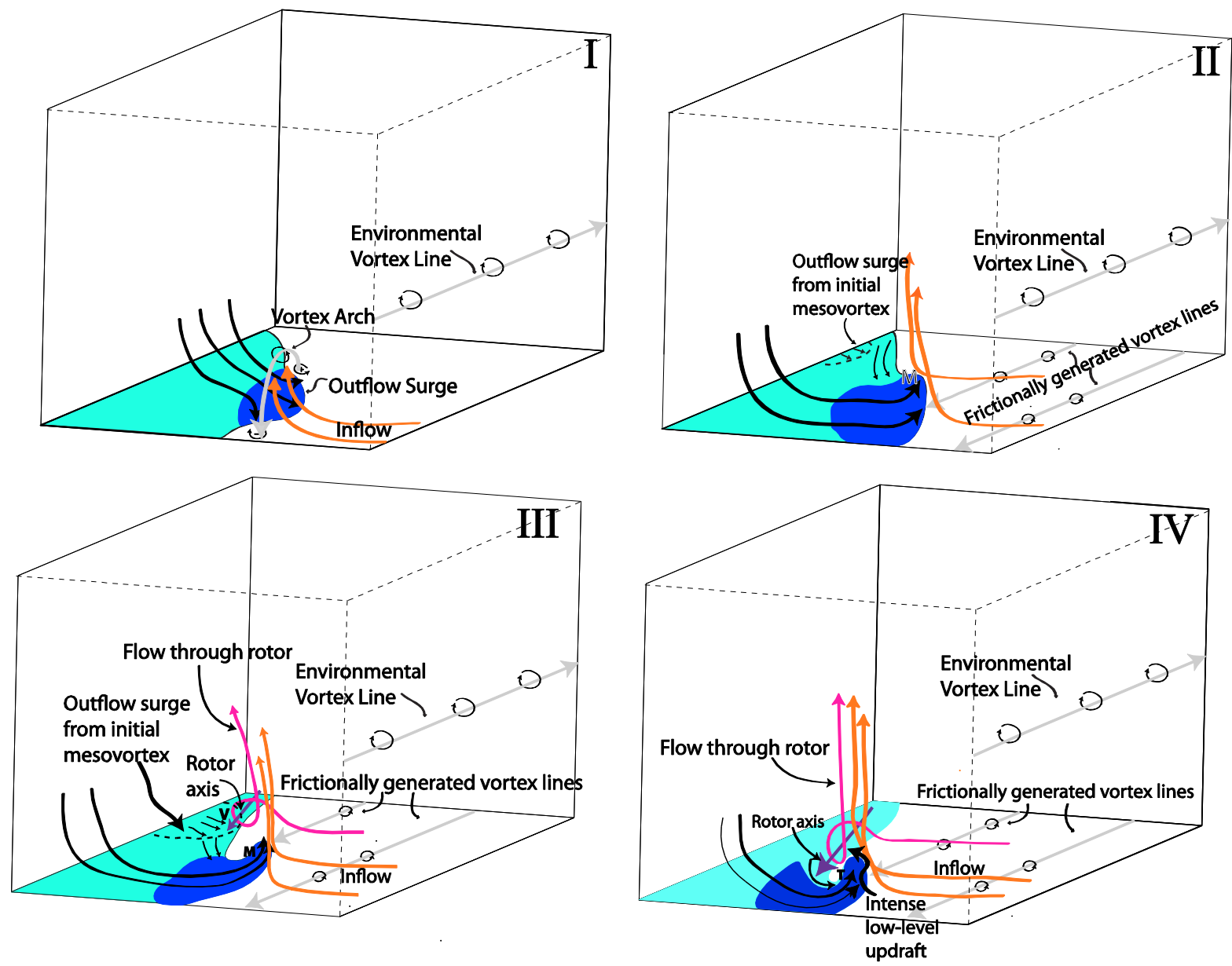

691

692

693

694

695

696

697

698

699

700

701

702

703

Fig. 7. Schematic of four-stage process leading up to genesis of a tornado-like vortex (TLV) associated with a mesovortex from Schenkman et al. (2012). Vertical vorticity couplet development is depicted in (I). (II) shows the development of a dominant cyclonic mesovortex and associated development of the frictionally-generated horizontal vorticity. (III) Illustrates the development of the rotor. TLV genesis is shown in (IV). The cyan shading represents the cold pool. The dark blue shading represents enhanced cold air within the cold pool bulge. Black arrows represent the surface flow trajectories. The orange arrows represent trajectories which enter the main updraft. The purple arrow in (III) and (IV) marks the horizontal rotor axis. The magenta arrows represent parcel trajectories that enter the rotor. Light gray vectors are idealized vortex lines. The ' $M$ ' represents the location of the mesovortex. The dotted curves in (II) and (III) mark the location of the enhanced westerly momentum associated with the dissipation of an mesovortex. The ' $v$ ' behind the outflow surge from the initial mesovortex in (III) marks the location of the small area of vertical vorticity moving through the rotor. The ' $T$ ' in (IV) marks the location of the TLV. 

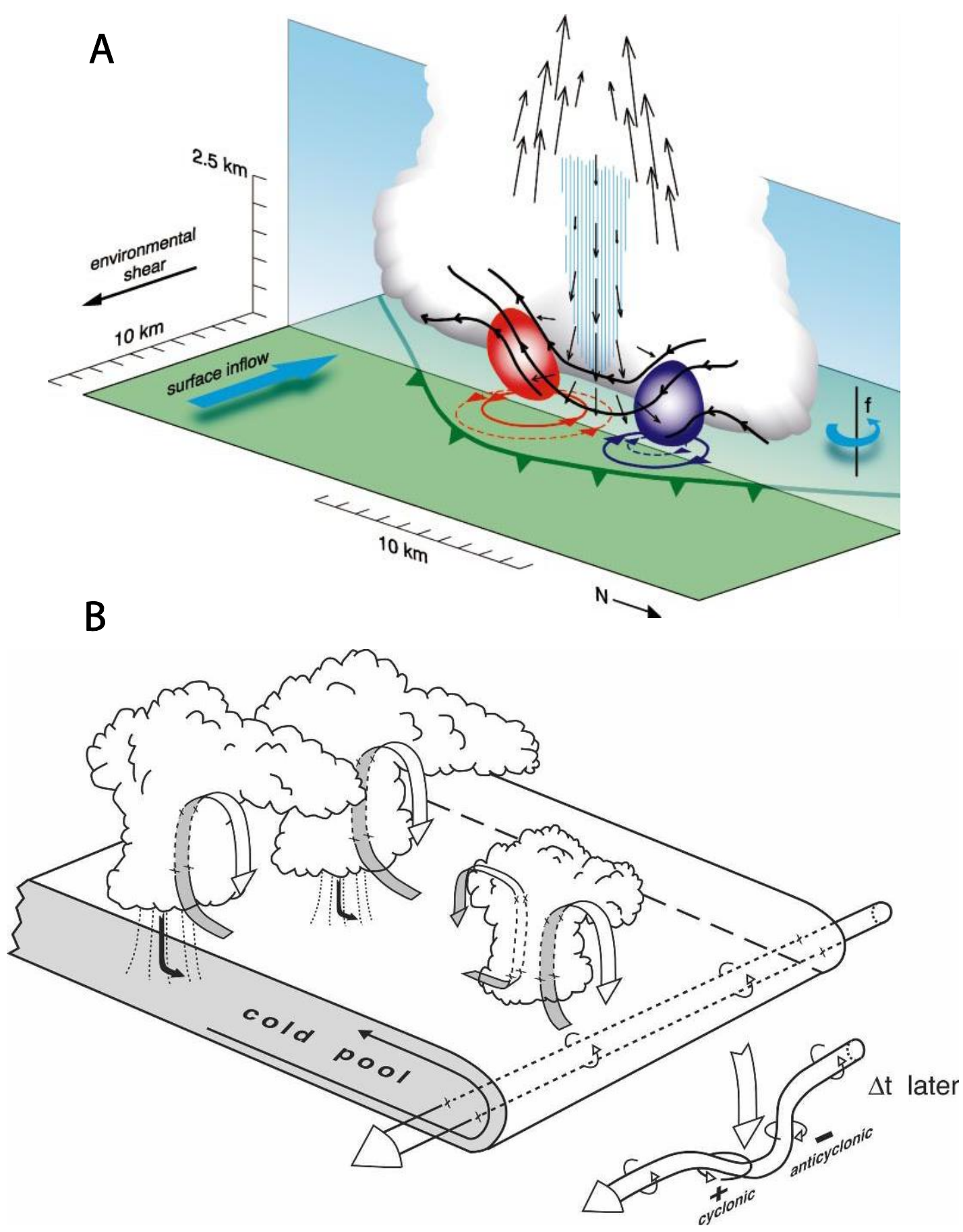

Fig. 8. Two conceptual models of the development of vorticity couplets via downward tilting of vortex lines. (a) Early stage conceptual model from Trapp and Weisman (2003), a rainy downdraft tilts baroclinically-generated vortex lines (black lines) downward to create cyclonic (red shading and lines) and anti-cyclonic (blue shading and lines) vertical vorticity. The green boundary represents the system gust front. (b) From Wakimoto et al. (2006b), downward tilting of vortex lines (tube at the edge of the cold pool) by mechanically forced downdrafts (downward pointing white arrows). This mechanical tilting of vortex lines results in a vortex couplet with the same orientation as that of (a). 

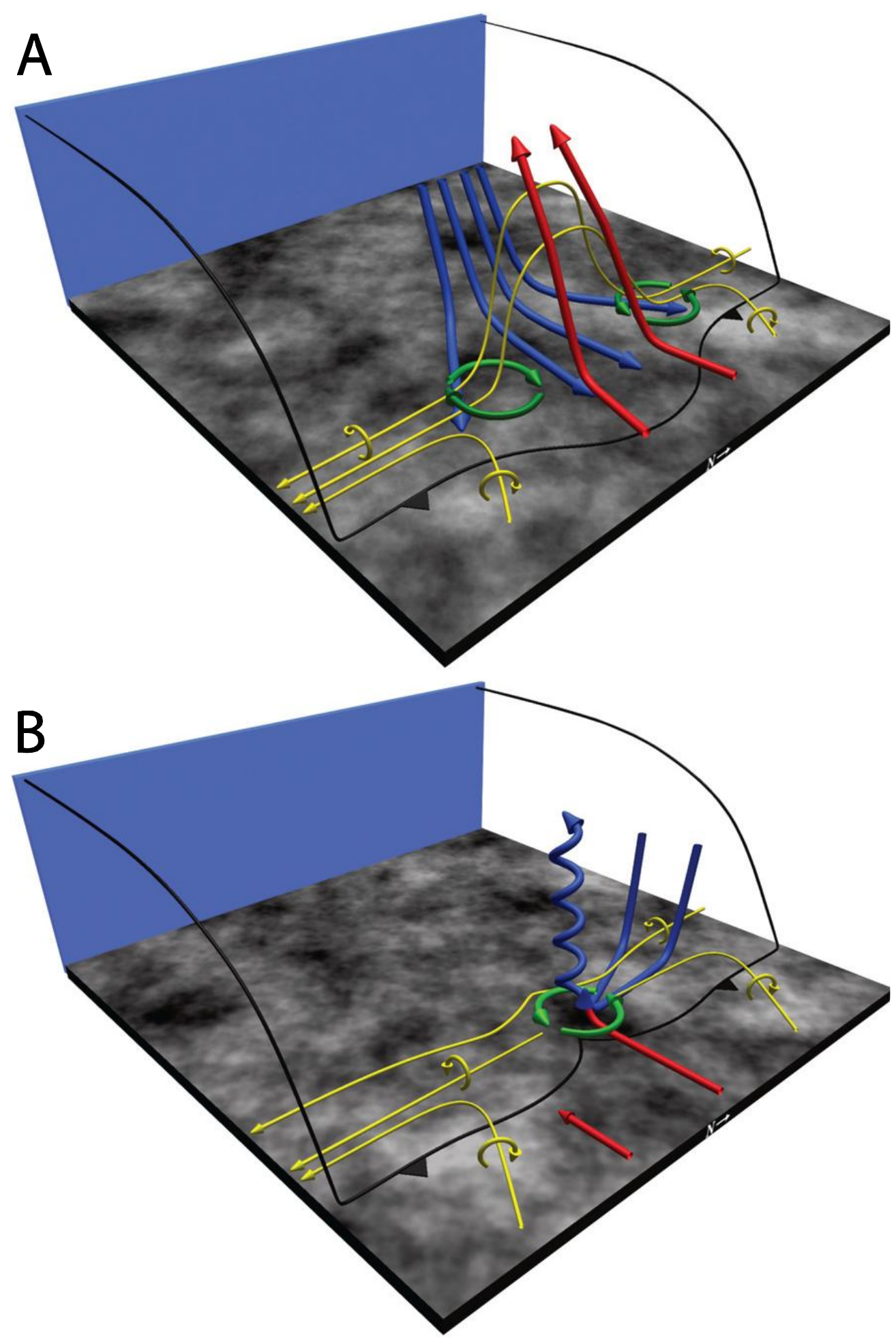

715 Fig. 9. Two Schematic for mesovortexgenesis from Atkins and St. Laurent (2009b). In (A), system-generated baroclinic vorticity (gold) is tilted upward by an updraft (red) at the leading edge of the cold pool (black). A vortex couplet (green) straddles the downdraft (blue) and updraft. In (B), a cyclonic-only mesovortex is generated by vorticity tilting in a downdraft along the gust front and subsequent rising motion. 


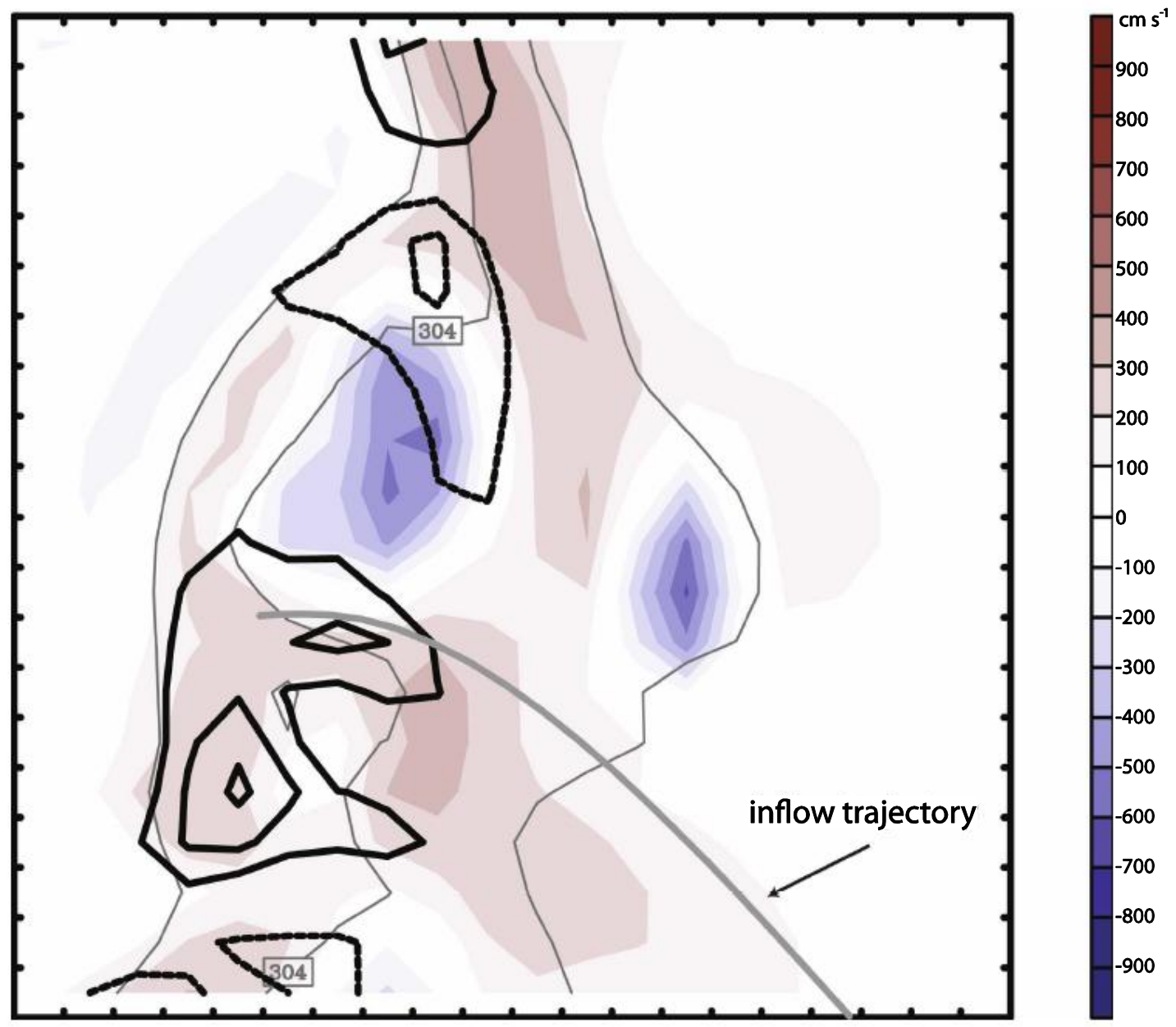

Fig. 10. Simulated vorticity couplet straddling a low-level downdraft at $400 \mathrm{~m}$ AGL. Cyclonic vorticity (solid black lines) is south of anti-cyclonic vorticity (dash black lines). Vertical velocity is shaded $\left(\mathrm{cm} \mathrm{s}^{-1}\right)$. Light gray lines are potential temperature isotherms. [From Wheatley and Trapp (2008)]. 


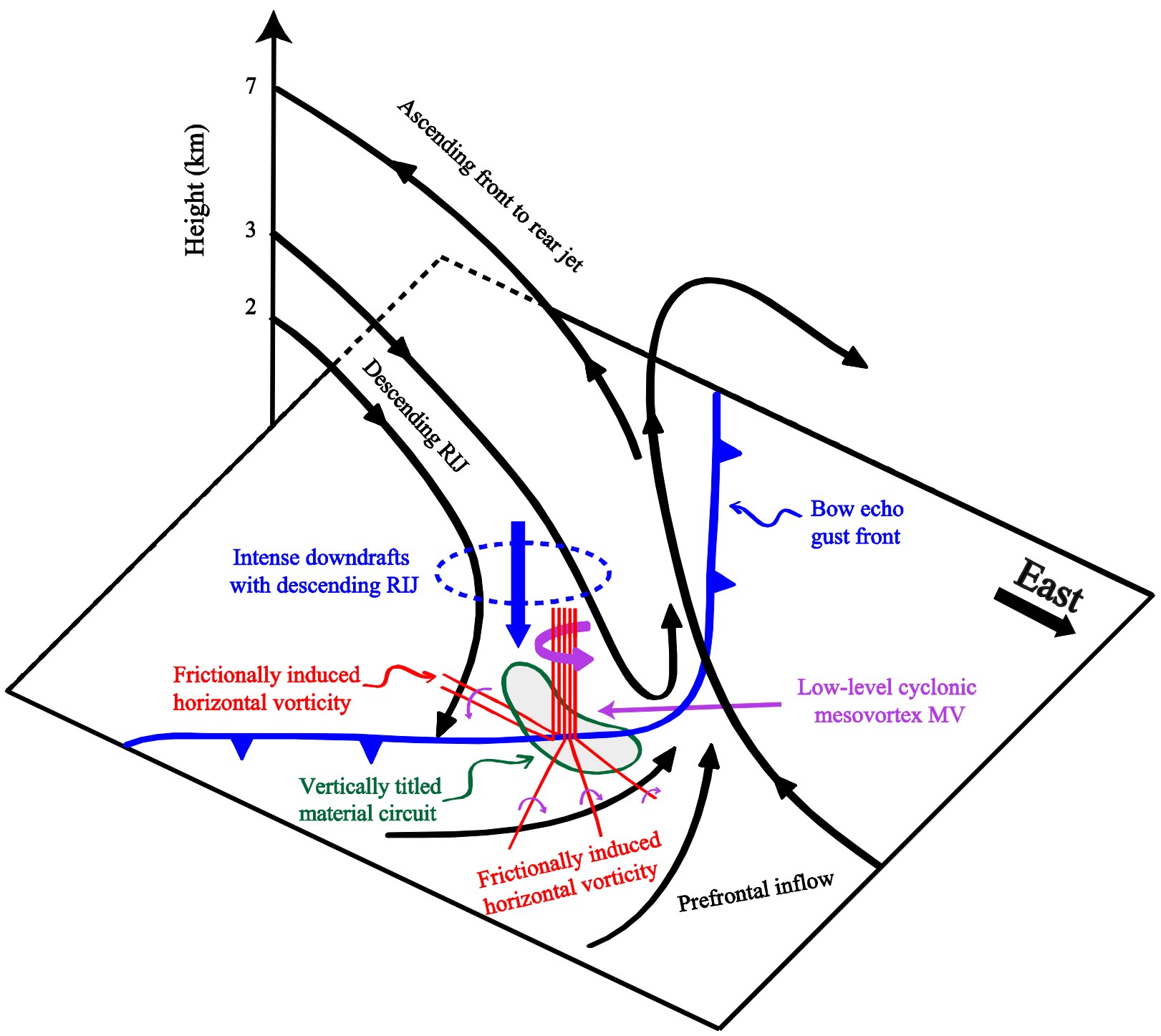

Fig. 11. Schematic from Xu et al. (2015b) showing mesovortexgenesis near the apex of a large bow echo. Red lines denote vortex lines. The mesovortex location is marked by the curved purple arrow. A material circuit enclosing the mesovortex is marked in green and shaded in grey. 

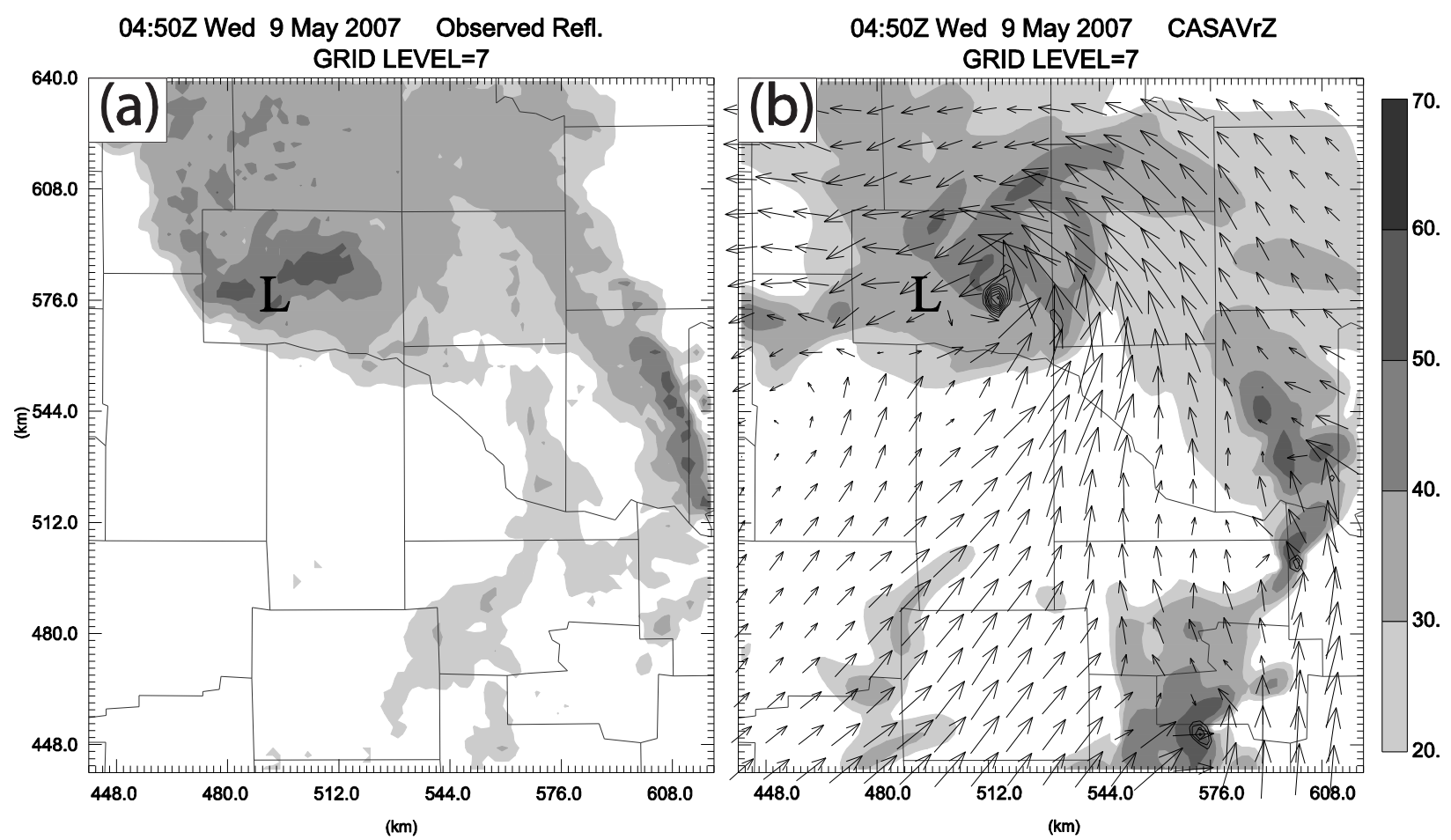

Fig. 12. Reflectivity at grid level 7 ( $1 \mathrm{~km} \mathrm{AGL}$ ) at 0450 UTC 9 May 2007 (a) observed radar mosaic and (b) $2 \mathrm{hr} 50$ min simulation that assimilated data from the WSR-88D and CASA radars. 'L' marks the approximate location of the observed line-end vortex. The vectors and contours in (b) are the horizontal wind and vertical vorticity, respectively. [Adapted from Schenkman et al. (2011a)]. 
Observed KOKC Vr at 0340 UTC

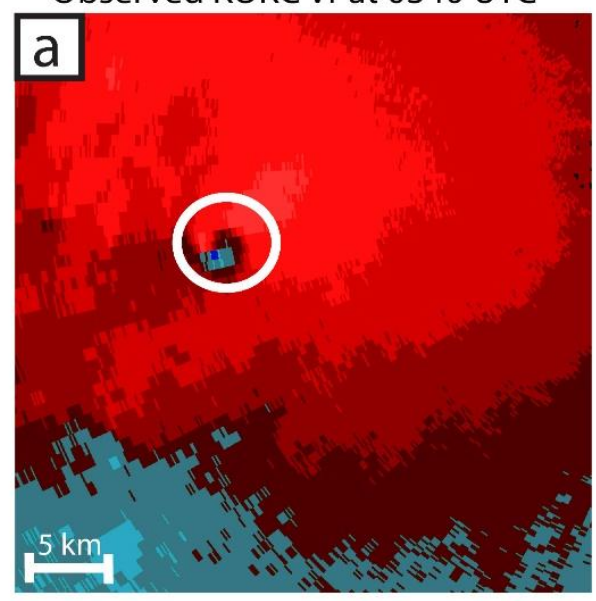

Simulated KOKC Vr CASAVrZ 0340 UTC

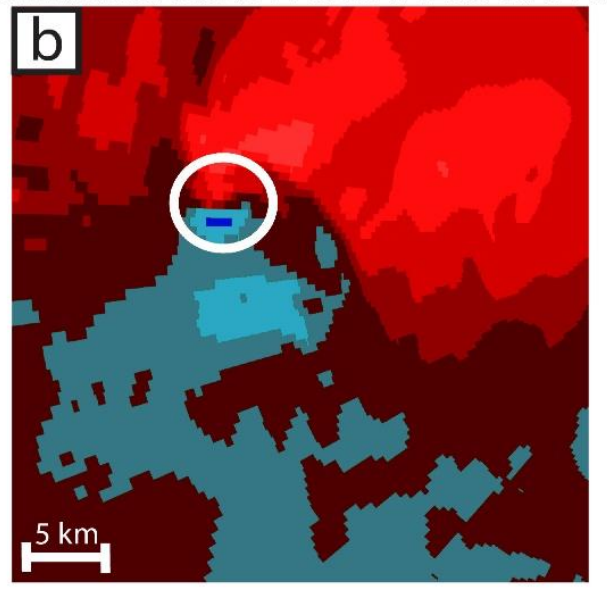

Simulated KOKC Vr 88DONLY 0340 UTC

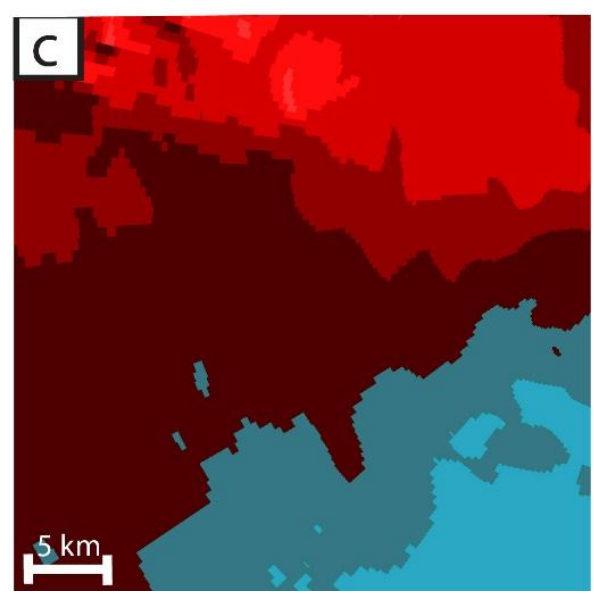

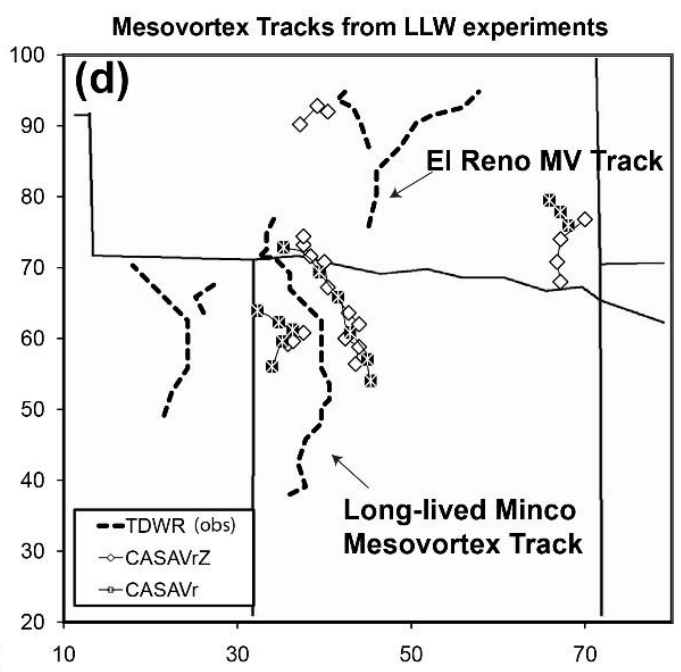
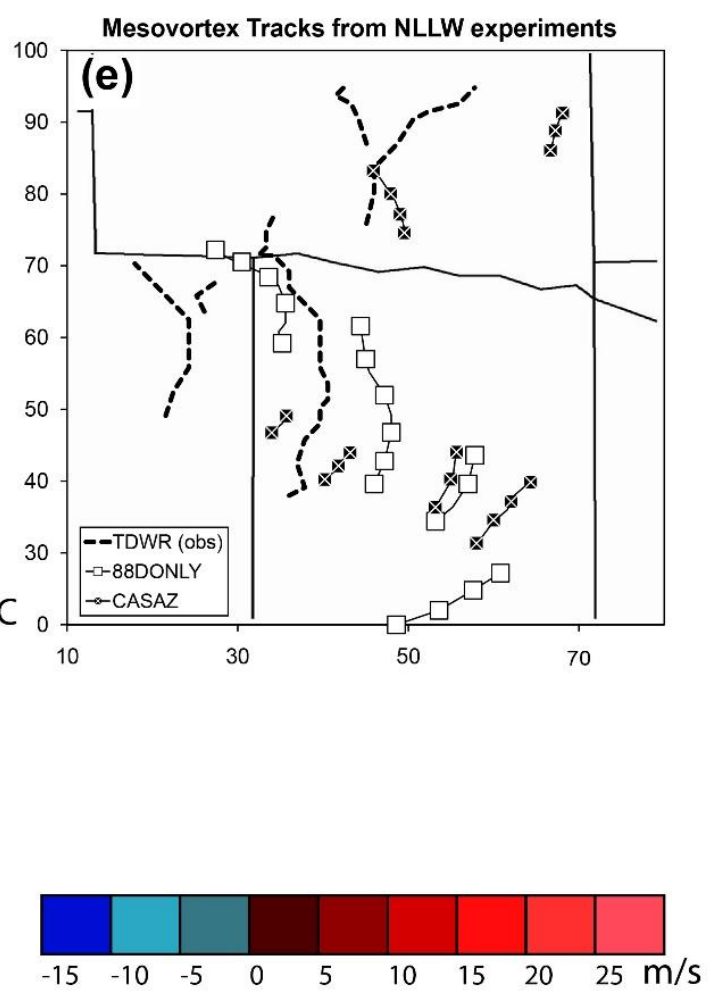

Fig. 13. (a) Observed radar radial velocity observed by the KOKC TDWR at 0340 UTC 9 May 2007. Simulated radar radial velocity from the KOKC TDWR at 340 UTC 9 May 2007 from (b) experiments that assimilated radial velocity from CASA and (c) experiments that only assimilated WSR-88D data. The panels on the right plot observed mesovortex tracks (dashed line) and simulated mesovortex tracks from (d) experiments that assimilated CASA radial velocity data and (e) those that assimilated WSR-88D data only. [Adapated from Schenkman et al. (2011b)]. 
a) Observed Reflectivity PAH 1756 UTC

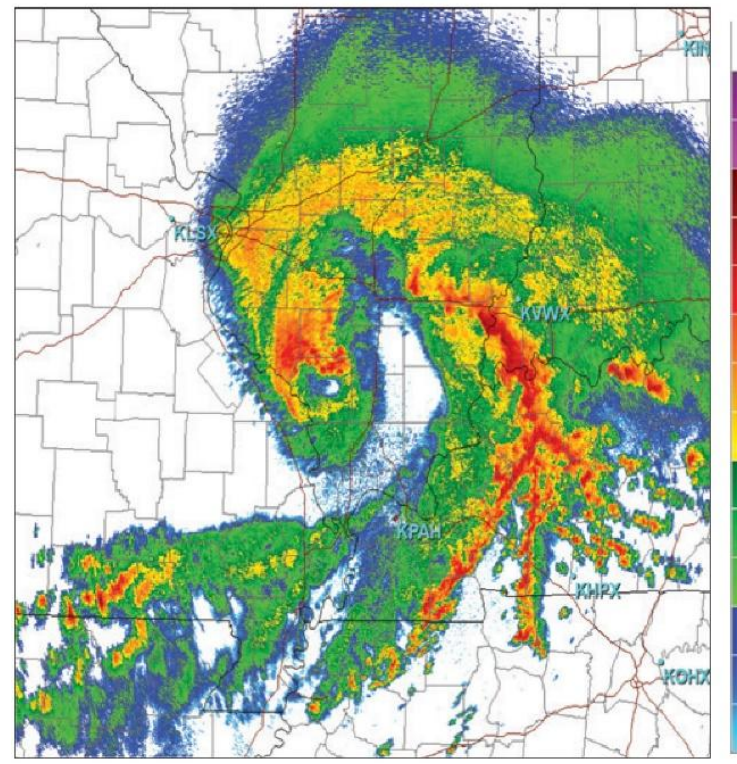

c) Observed MV tracks and reflectivity

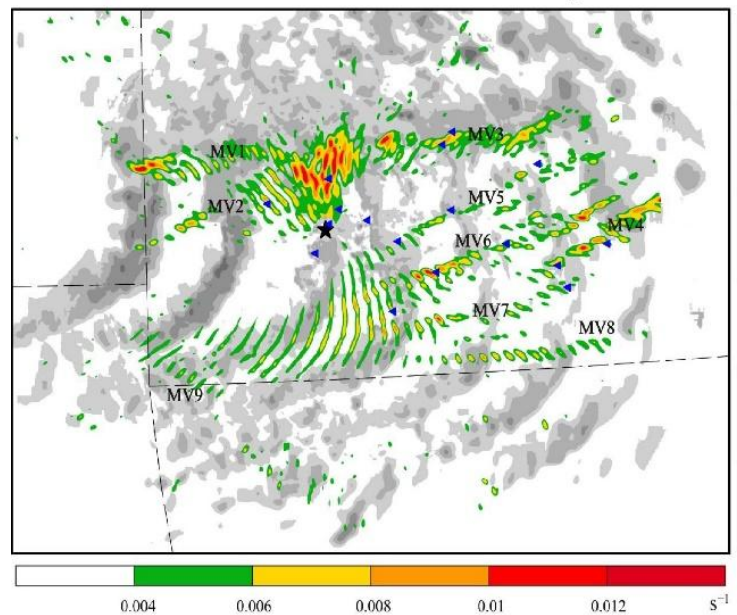

b) Model Reflectivity 1545 UTC

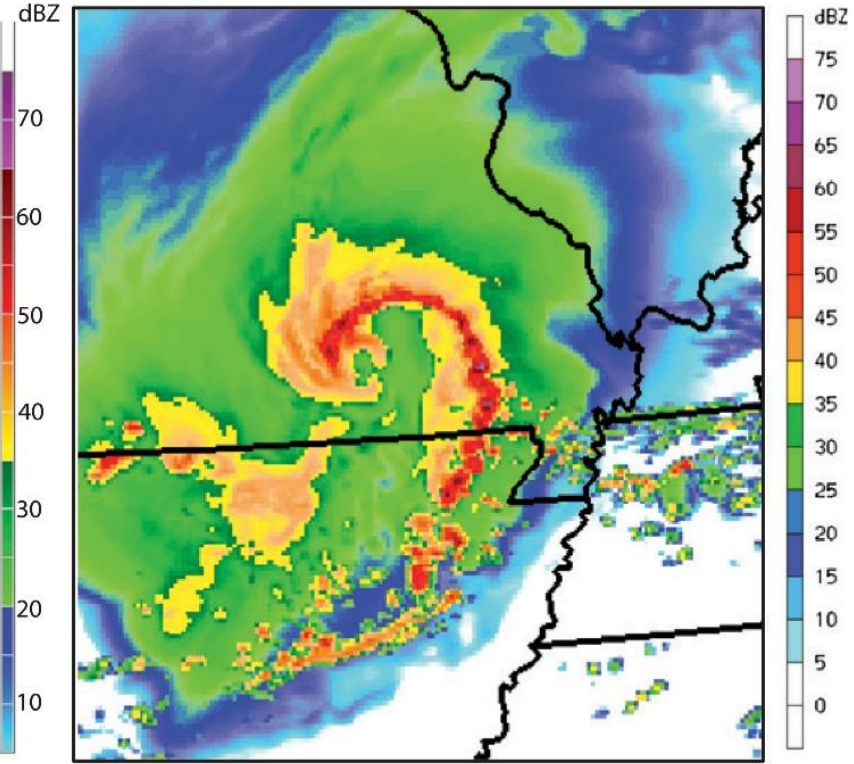

d) Simulated MV tracks and reflectivity

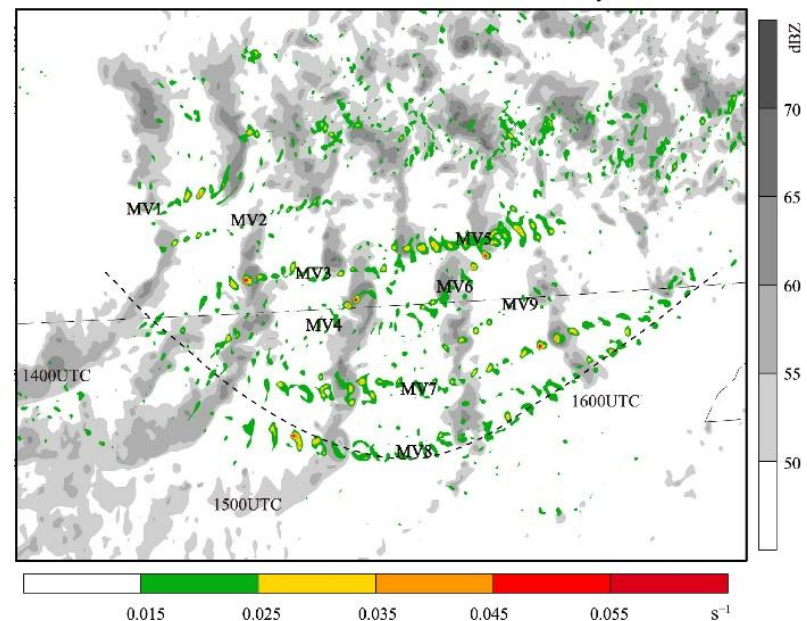

746

747

748

749

750

751

Fig. 14. (a) Observed reflectivity from KPAH at 1756 UTC 8 May 2009. (b) Simulated reflectivity at 1545 UTC 8 May 009. [From Weisman et al. (2013)]. (c) Observed reflectivity (grayscale shading) and mesovortex tracks and (d) simulated mesovortex tracks and reflectivity [Adapted from Xu et al. (2015a)]. The color shading represents absolute velocity azimuthal shear in (c) and vertical vorticity in (d). Blue triangles in (c) are locations of reported tornadoes. The black star in (c) is the location of KPAH. 